\title{
Numerical Simulation of Fracture Behavior of Brittle Solids under I/III Loading
}

\author{
Zhitao Zhang $\mathbb{D},^{1,2}$ Haijun Wang $\mathbb{D}^{1,2}$ and Shuyang $Y u^{3}$ \\ ${ }^{1}$ Materials and Structural Engineering Department, Nanjing Hydraulic Research Institute, Nanjing 210019, China \\ ${ }^{2}$ State Key Laboratory of Hydrology-Water Resources and Hydraulic Engineering, Nanjing 210019, China \\ ${ }^{3}$ College of Water Conservancy and Hydropower Engineering, Hohai University, Nanjing 210098, China \\ Correspondence should be addressed to Haijun Wang; hjwang@nhri.cn
}

Received 11 December 2019; Revised 20 June 2020; Accepted 13 July 2020; Published 3 August 2020

Academic Editor: Fabio Di Trapani

Copyright ( $\odot 2020$ Zhitao Zhang et al. This is an open access article distributed under the Creative Commons Attribution License, which permits unrestricted use, distribution, and reproduction in any medium, provided the original work is properly cited.

This study used numerical analysis to carry out a large number of numerical model calculations based on a new semicircular bend (SCB) model. Instead of existing numerical computation methods ( $J$-integral), the $M$-integral method was used to calculate the mixed mode fracture parameters $\left(K_{\mathrm{I}}, K_{\mathrm{II}}\right.$, and $\left.K_{\mathrm{III}}\right)$, investigate the influence of the geometry and material parameters on the fracture behavior under mixed mode I/III loading, and predict the fracture path. The results revealed that the limitations in the scope of the mixity parameter $M^{e}$ in the previous studies can be overcome to a certain extent. The range of $M^{e}$ was established under different Poisson ratios and can be used as a reference for actual material testing. The simulation path is in good agreement with the experimentally obtained fracture path, and the proposed method can be used to simulate the fracture path under mixed mode I/III loading.

\section{Introduction}

Fracture mechanics focuses on the mechanical properties of materials and structures with cracks. The cracks can be inherent in the material or generated during manufacturing, and the existence and growth of these cracks decrease the bearing capacity of the structure or even cause its failure.

The semicircular bend (SCB) is a classic fracture mechanics test that is widely used to investigate solid materials owing to its inherent favorable properties, such as its simplicity, minimal machining requirement, testing convenience, and ease of reaching tensile failure as reported by Mahinda and Kuruppu [1]. The SCB specimen was proposed by Chong [2-4] and has been gradually improved. Additionally, it has been widely used for determining the fracture parameter $K_{\mathrm{IC}}$, and its potential application in the mixed mode fracture test has been investigated [5-9]. The investigation of the SCB specimen mainly includes fracture toughness testing and determining the fracture parameters [10-28], discussing and revising the limitations of the extension criteria $[11,13,16,25,29,30]$, and numerically predicting the fracture path $[14,20,23,27,31-33]$. Owing to the limitation of the specimen shape, the abovementioned studies focused on the fracture parameters of mode I, mode II, and mixed mode I/II. The out-of-plane shearing mode (mode III) has not been as extensively investigated, although it exists in actual situations. Additionally, existing testing methods are highly dependent on the machine and test fixture and mainly focus on metal materials, ceramics, and other artificial materials [34-38].

Because engineering accidents, such as rock fracture and pavement rupture, occur frequently, the investigation of mode III has attracted a great amount of interest. Moreover, observations have shown that flat cracks tend to reorient themselves to oblique planes during propagation and can grow under mixed-mode I/III conditions [39, 40]. Therefore, test methods and specimens under the abovementioned conditions have been proposed for rocks, concrete, asphalt, and other materials. Berto et al. applied the strain energy density (SED) criterion to pure modes and mixed mode I/III loading conditions [41-45]. Aliha et al. [46-49] proposed a new test configuration called the ENDB specimen for 
investigating the fracture behavior under the mixed mode I/ III. Additionally, this configuration can achieve an arbitrary composition of mode I and mode III. Notably, however, more variables need to be controlled in the experiment. Linul et al. [50, 52] conducted experiments with foam materials and obtained fracture toughness data for the mixed modes I/II and I/III. Subsequently, Pirmohammad [53] proposed a new SCB specimen type, whose mixed mode I/III fracture behavior is easier to investigate using the proposed specimens with a tilted crack and further investigated the fracture behavior of asphalt concrete at low temperature.

In previous studies $[49,53]$, the change of the geometric parameters and material parameters had a significant effect on the mixed mode I/II loading of SCB specimens. However, only few studies have investigated whether the abovementioned conditions affect the fracture behavior of mode I/ III. In this study, a relatively accurate numerical analysis method was used to investigate the feasibility of realizing mixed mode I/III loading and the effects of the specimen's geometric parameters and Poisson's ratio on these loading conditions. Finally, the fracture path was simulated and analyzed based on the fracture parameters.

\subsection{Numerical Analyses}

In the previous numerical studies $[41,53,54]$, the fracture parameters were directly calculated using the $J$-integral method in the Abaqus software. However, according to Li, the $J$-integral is more suitable for pure mode I fracture problems [55]. For the mixed mode fracture, the equivalent domain equation of the interaction integral ( $M$-integral) $[56,57]$ is the most accurate method for calculating the fracture parameters. The SCB macrostructural model was established in Abaqus; then, the mesh was remeshed using adaptive grid technology in franc3D, and the bottom inclined crack was inserted. Finally, different $K_{\mathrm{I}}, K_{\mathrm{II}}$, and $K_{\mathrm{III}}$ values were obtained by the $M$-integral.

The schematic diagram of the semicircular geometry is shown in Figure 1; the radius of the SCB specimen $(R)$, specimen thickness $(t)$, and half of the loading span $(S)$ in the SCB test were determined by modeling in Abaqus. Figure 2(a) shows the Abaqus grid model with C3D10 cells. Figure 2(b) shows the mesh model after defining the crack length $(a)$ and the angle of $\operatorname{crack}(\alpha)$. Figure 3 shows the element distribution and crack tip types. A singular element was inserted at the crack tip, and conservation integral evaluation was carried out around the two element rings at the crack front. The inner ring of a 15-node singular wedge-shaped element and the outer ring of a 20-node hexahedral element with symmetric meshes were used to reduce the local discrete errors. Notably, the fracture parameters $\left(K_{\mathrm{I}}, K_{\mathrm{II}}\right.$, and $\left.K_{\mathrm{III}}\right)$ calculated at the surface contact zone are not reliable, because the local plane strain condition is no longer maintained. The element at the crack tip may be severely distorted, as shown in Figure 2(c), and the grid symmetry may be lost. Moreover, Figure 2(c) shows that the transition region at the crack tip has pyramidal elements, while the global region is a tetrahedral element type.
In the created models, radius of SCB specimen $(R)$, specimen thickness $(t)$, and applied load $(P)$ are invariants, respectively, $75 \mathrm{~mm}, 32 \mathrm{~mm}$, and $40.3437 \mathrm{kN}$. Geometrical and material parameters such as the half of loading point span ratio $(S / R)$, crack length ratio $(a / R)$, crack angle $(\alpha)$, and Poisson's ratio $(v)$ were varied in the following ranges: $S / R=$ $\{0.4,0.6,0.8\}, a / R=\{0.2,0.26,0.3\}, \alpha=\{0,5,10,15,20,25,30$, $35,40,45,48,50,52,55,60\}$, and $v=\{0.1,0.2,0.3,0.4\}$. When $\alpha$ is $0^{\circ}$, it is pure mode I fracture. With the increase of $\alpha$, mixed mode I/III fracture can be obtained.

The fracture parameters $\left(K_{\mathrm{I}}, K_{\mathrm{II}}\right.$, and $\left.K_{\mathrm{III}}\right)$ can be directly extracted using the following expressions. For linear analysis, we can add two valid solutions, and the result is a valid solution, as follows:

$$
\begin{aligned}
& \sigma_{i j}=\sigma_{i j}^{(1)}+\sigma_{i j}^{(2)}, \\
& \varepsilon_{i j}=\varepsilon_{i j}^{(1)}+\varepsilon_{i j}^{(2)}, \\
& u_{i j}=u_{i j}^{(1)}+u_{i j}^{(2)} .
\end{aligned}
$$

Let us consider the corner mark (1) solutions as the Abaqus results and the corner mark (2) solutions as the solutions that we can select. These can be substituted into the expression for the $J$-integral as follows:

$$
\begin{aligned}
\bar{J}= & \int_{\Gamma}\left(\sigma_{i j}^{(1)} \frac{\partial_{u_{i}}^{(1)}}{\partial_{x_{1}}}+\sigma_{i j}^{(1)} \frac{\partial_{u_{i}}^{(2)}}{\partial_{x_{1}}}+\sigma_{i j}^{(2)} \frac{\partial_{u_{i}}^{(1)}}{\partial_{x_{1}}}+\sigma_{i j}^{(2)} \frac{\partial_{u_{i}}^{(2)}}{\partial_{x_{1}}}-W^{(1)} \delta_{1 j}\right. \\
& \left.-W^{(2)} \delta_{1 j}-W^{(1,2)} \delta_{1 j}\right) \frac{\partial_{q}}{\partial_{x_{j}}} \mathrm{~d} s
\end{aligned}
$$

According to Betti's reciprocal theorem, the following relationship holds:

$$
W^{(1,2)}=\sigma_{i j}^{(1)} \varepsilon_{i j}^{(2)}=\sigma_{i j}^{(2)} \varepsilon_{i j}^{(1)} .
$$

By collecting terms, the following relationship can be obtained:

$$
\bar{J}=\bar{J}^{(1)}+\bar{J}^{(2)}+\bar{M}^{(1,2)}
$$

with

$$
\begin{aligned}
\bar{J}^{(1)} & =\int_{\Gamma}\left(\sigma_{i j}^{(1)} \frac{\partial_{u_{i}}^{(1)}}{\partial_{x_{1}}}-W^{(1)} \delta_{1 j}\right) \frac{\partial_{q}}{\partial_{x_{j}}} \mathrm{~d} s, \\
\bar{J}^{(2)} & =\int_{\Gamma}\left(\sigma_{i j}^{(2)} \frac{\partial_{u_{i}}^{(2)}}{\partial_{x_{1}}}-W^{(2)} \delta_{1 j}\right) \frac{\partial_{q}}{\partial_{x_{j}}} \mathrm{~d} s, \\
\bar{M}^{(1,2)} & =\int_{\Gamma}\left(\sigma_{i j}^{(1)} \frac{\partial_{u_{i}}^{(2)}}{\partial_{x_{1}}}+\sigma_{i j}^{(2)} \frac{\partial_{u_{i}}^{(1)}}{\partial_{x_{1}}}-W^{(1,2)} \delta_{1 j}\right) \frac{\partial_{q}}{\partial_{x_{j}}} \mathrm{~d} s .
\end{aligned}
$$

The crack-tip energy release rates can be determined from Irwin's crack closure integral for small scale yielding assuming plane strain conditions, as follows: 


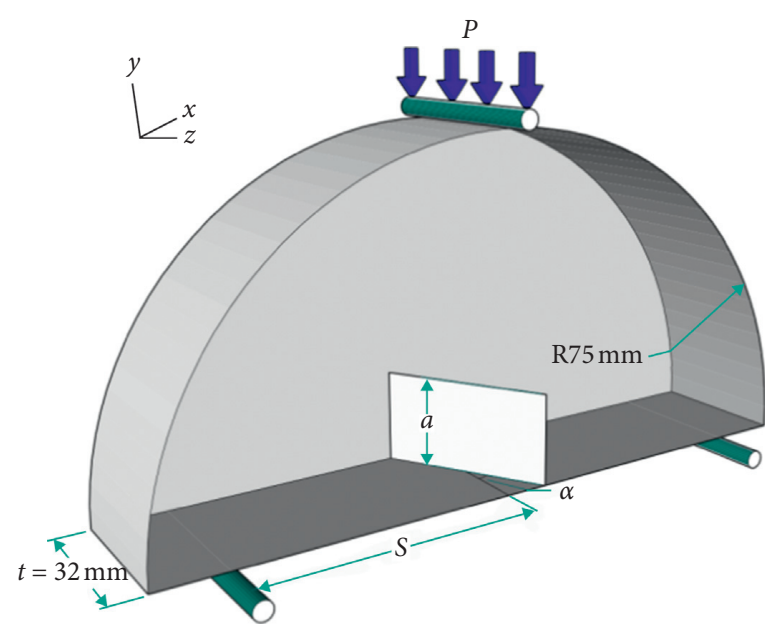

(a)

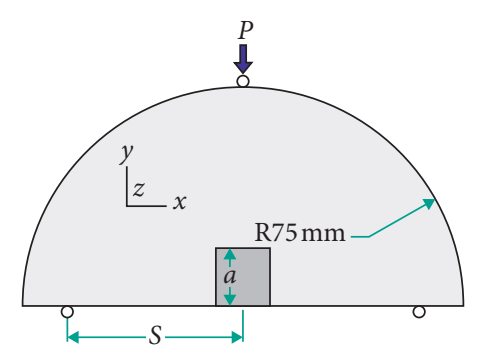

(b)

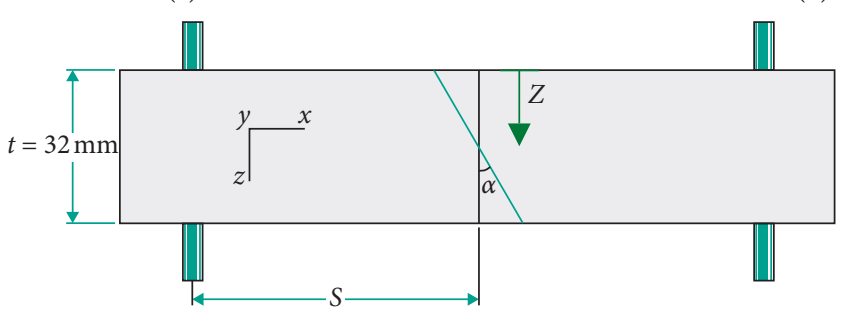

(c)

FIgURE 1: Geometry and loading configuration of SCB specimen. (a) Three-dimensional view; (b) front view; (c) top view.

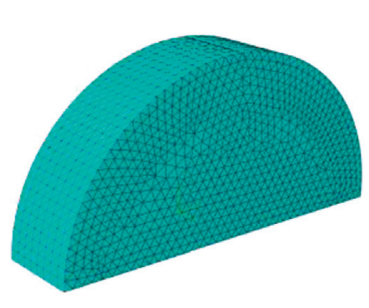

(a)

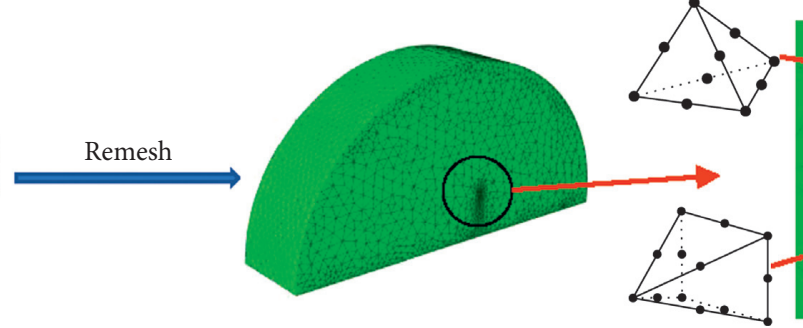

(b)

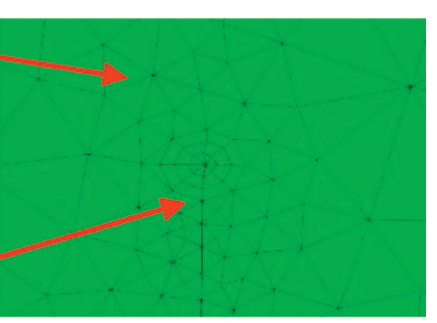

(c)

Figure 2: Grid model of SCB specimen. (a) Abaqus mesh. (b) Franc3D mesh. (c) Crack tip mesh.

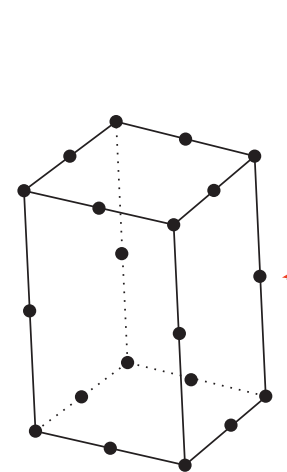

(a)

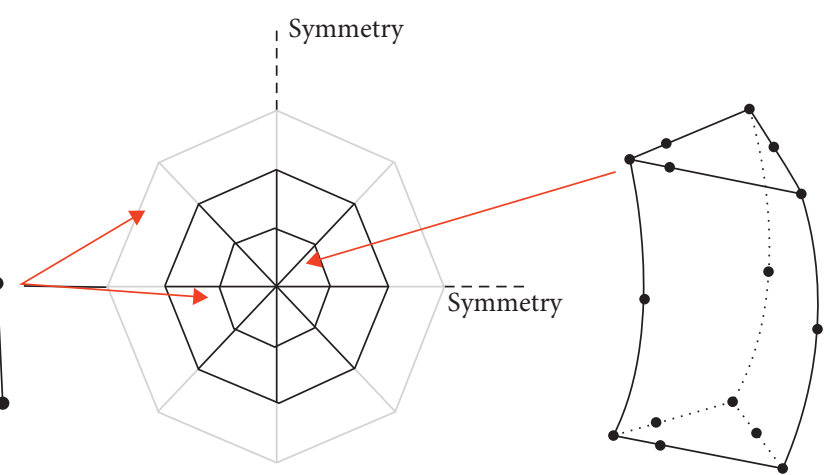

(b)

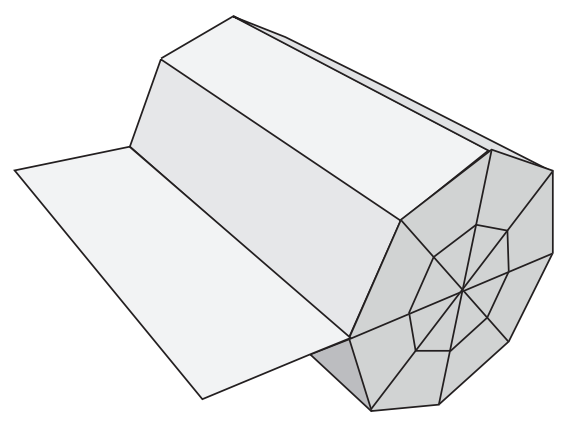

(d)

Figure 3: Element distribution and crack tip types. (a) Hexahedral element. (b) Element rings. (c) Singular wedge-shaped element. (d) Integral domain. 


$$
\begin{aligned}
G=J & =\frac{1-v^{2}}{E} K_{\mathrm{I}}^{2}+\frac{1-v^{2}}{E} K_{\mathrm{II}}^{2}+\frac{1+v}{E} K_{\mathrm{III}}^{2}, \\
K_{\mathrm{I}} & =K_{\mathrm{I}}^{(1)}+K_{\mathrm{I}}^{(2)} \\
K_{\mathrm{II}} & =K_{\mathrm{II}}^{(1)}+K_{\mathrm{II}}^{(2)} \\
K_{\mathrm{III}} & =K_{\mathrm{III}}^{(1)}+K_{\mathrm{III}}^{(2)} .
\end{aligned}
$$

By substituting into the expression for the energy release rate, we obtain the following relationship:

$$
\begin{aligned}
J^{(1)} & =\frac{1-v^{2}}{E}\left(K_{\mathrm{I}}^{(1)}\right)^{2}+\frac{1-v^{2}}{E}\left(K_{\mathrm{II}}^{(1)}\right)^{2}+\frac{1+v}{E}\left(K_{\mathrm{III}}^{(1)}\right)^{2}, \\
J^{(2)} & =\frac{1-v^{2}}{E}\left(K_{\mathrm{I}}^{(2)}\right)^{2}+\frac{1-v^{2}}{E}\left(K_{\mathrm{II}}^{(2)}\right)^{2}+\frac{1+v}{E}\left(K_{\mathrm{III}}^{(2)}\right)^{2}, \\
\bar{M}^{(1,2)} & =\frac{1-v^{2}}{E} K_{\mathrm{I}}^{(1)} K_{\mathrm{I}}^{(2)}+\frac{1-v^{2}}{E} K_{\mathrm{II}}^{(1)} K_{\mathrm{II}}^{(2)}+\frac{1+v}{E} K_{\mathrm{III}}^{(1)} K_{\mathrm{III}}^{(2)} .
\end{aligned}
$$

By equating the two definitions for the $M$-Integral, we can obtain the following relationship:

$$
\int_{\Gamma} \frac{\left(\sigma_{i j}^{(1)}\left(\partial_{u_{i}}^{(2)} / \partial_{x_{1}}\right)+\sigma_{i j}^{(2)}\left(\partial_{u_{i}}^{(1)} / \partial_{x_{1}}\right)-W^{(1,2)} \delta_{1 j}\right) \partial_{q} / \partial_{x_{j}} \mathrm{~d} s}{A_{q}}=\bar{M}^{(1,2)}
$$

where

$$
A_{q}=\int_{L} q_{t}\left(x_{3}\right) \mathrm{d} x_{3}
$$

We used the Abaqus results for solution (1) and selected the three simple auxiliary solutions (2a), (2b), and (2c). Table 1 presents the values of the asymptotic solutions for the pure mode cracks.

From the analytical expressions for the crack-front fields, we can obtain the following:

$$
\sigma^{(2 \mathrm{a})}, \sigma^{(2 \mathrm{~b})}, \sigma^{(2 \mathrm{c})}, \varepsilon^{(2 \mathrm{a})}, \varepsilon^{(2 \mathrm{~b})}, \varepsilon^{(2 \mathrm{c})}, u^{(2 \mathrm{a})}, u^{(2 \mathrm{~b})}, u^{(2 \mathrm{c})} .
$$

By substituting the value of $K^{(2)}$, reported in Table 1, in equation (9), we can obtain three equations for the unknown $K^{(1)}$ 's, as follows:

$$
\left[\begin{array}{ccc}
\frac{2\left(1-v^{2}\right)}{E} & 0 & 0 \\
0 & \frac{2\left(1-v^{2}\right)}{E} & 0 \\
0 & 0 & \frac{2(1+v)}{E}
\end{array}\right]\left\{\begin{array}{c}
K_{\mathrm{I}}^{(1)} \\
K_{\mathrm{II}}^{(1)} \\
K_{\mathrm{III}}^{(1)}
\end{array}\right\}=\left\{\begin{array}{c}
\frac{\bar{M}^{(1,2 \mathrm{a})}}{A_{q}} \\
\frac{\bar{M}^{(1,2 \mathrm{~b})}}{A_{q}} \\
\frac{\bar{M}^{(1,2 \mathrm{c})}}{A_{q}}
\end{array}\right\},
$$

where $v$ is Poisson's ratio, $\Gamma$ is the integral curve away from the tip of the crack, $\delta_{1 j}$ is the Kronecker delta, $q$ is a function
TABLE 1: The asymptotic solution of pure mode crack is evaluated.

\begin{tabular}{llll}
\hline & $K_{\mathrm{I}}$ & $K_{\mathrm{II}}$ & $K_{\mathrm{III}}$ \\
\hline $\mathrm{a}$ & 1.0 & 0.0 & 0.0 \\
$\mathrm{~b}$ & 0.0 & 1.0 & 0.0 \\
$\mathrm{c}$ & 0.0 & 0.0 & 1.0 \\
\hline
\end{tabular}

that is equal to one at the crack tip and zero on the boundary of the integration domain and can be interpreted as a virtual crack extension, $q_{t}$ is the value of the $q$ function along the crack front, and $L$ is the length of the cylindrical domain along the crack front. $\sigma_{i j}^{(1)}, \varepsilon_{i j}^{(1)}, u_{i j}^{(1)}$ is the solution provided by the Abaqus results.

$K_{\mathrm{I}}, K_{\mathrm{II}}$, and $K_{\mathrm{III}}$ can be expressed by the dimensionless parameters $Y_{\mathrm{I}}, Y_{\mathrm{II}}$, and $Y_{\mathrm{III}}$, as follows:

$$
\begin{gathered}
Y_{\mathrm{I}}=\frac{K_{\mathrm{I}}}{\sqrt{\pi a}} \frac{2 R t}{P}, \\
Y_{\mathrm{II}}=\frac{K_{\mathrm{II}}}{\sqrt{\pi a}} \frac{2 R t}{P}, \\
Y_{\mathrm{III}}=\frac{K_{\mathrm{III}}}{\sqrt{\pi a}} \frac{2 R t}{P} .
\end{gathered}
$$

To verify that the numerical simulation method can accurately realize mixed I/III mode fracturing, the $K_{\mathrm{I}}, K_{\mathrm{II}}$, and $K_{\text {III }}$ of the crack tip along the specimen thickness were adopted after normalization processing as shown in Figure 4. Here, $K_{n}(n=\mathrm{I}, \mathrm{II}, \mathrm{III})$ is the fracture parameter and $K_{\mathrm{Im}}$ is the maximum value of mode $\mathrm{I}$. The crack length ratio $(a / R)$ of the model is 0.26 , one half of the loading point span ratio $(S / R)$ is 0.8 , and the crack angle $(\alpha)$ is $0^{\circ}, 20^{\circ}, 40^{\circ}$, and $60^{\circ}$, respectively.

Figure 4(a) shows that, when $\alpha$ was $0^{\circ}$, fracture occurred under the pure mode I condition; $K_{\mathrm{I}}$ along the direction of the specimen thickness remained approximately unchanged within a certain range $(0.1<z / t<0.9)$ and declined in the free surface, which is consistent with the numerical simulation results reported by Aliha and Saghafi [54]. Moreover, $z / t$ was considered as 0.5 for the $K_{\mathrm{I}}$ value of the specimen.

Figures $4(\mathrm{~b})-4(\mathrm{~d})$ shows that, as $\alpha$ increased, the effects of modes I and III dominated within a certain range $(0.2<z$ l $t<0.8)$ along the thickness direction of the specimen. The proportion of mode II was small and could be ignored when $z / t$ was 0.5 , which is consistent with previously reported numerical analysis results [46-49]. Considering that the surface contact zone calculation of $K_{\mathrm{I}}, K_{\mathrm{II}}$, and $K_{\mathrm{III}}$ is not reliable, and according to the traditional definition of the singular stress field close to the free surface, it is widely accepted that the crack tip stress field is different, as discussed by Bažant and Estenssoro [58]. Hence, $K_{\mathrm{I}}, K_{\mathrm{II}}$, and $K_{\text {III }}$ close to the free surface should not be considered, and this numerical method is valid and feasible for testing the mixed mode I/III fracture. Notably, in mixed mode I/III loading, the crack tip along the thickness of the specimen completely corresponds to the point where $z / t$ is 0.5 . Therefore, subsequent calculations considered this point as the value of $K_{\mathrm{I}}, K_{\mathrm{II}}$, and $K_{\mathrm{III}}$ of the specimen. 


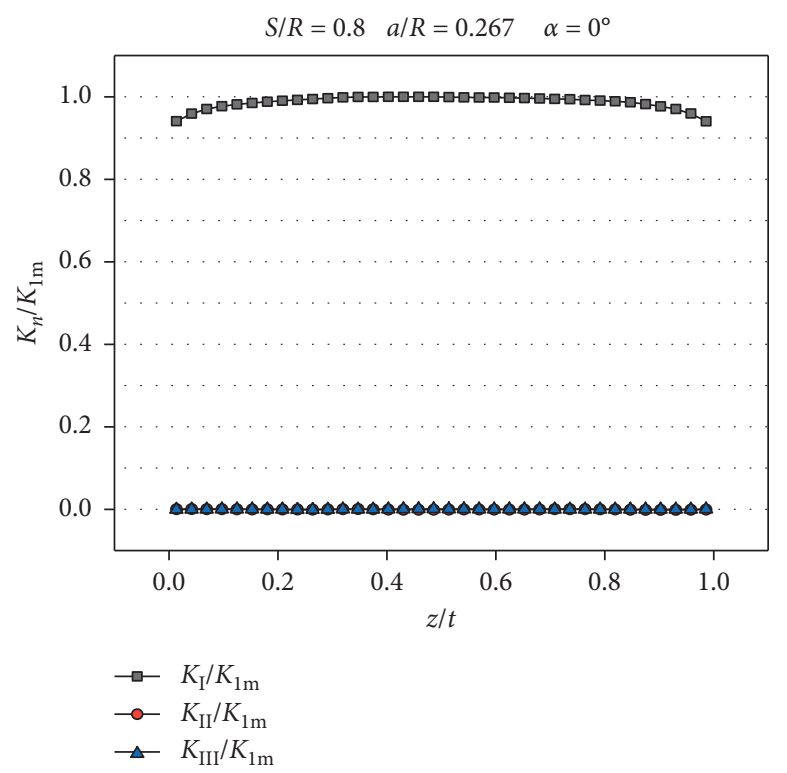

(a)

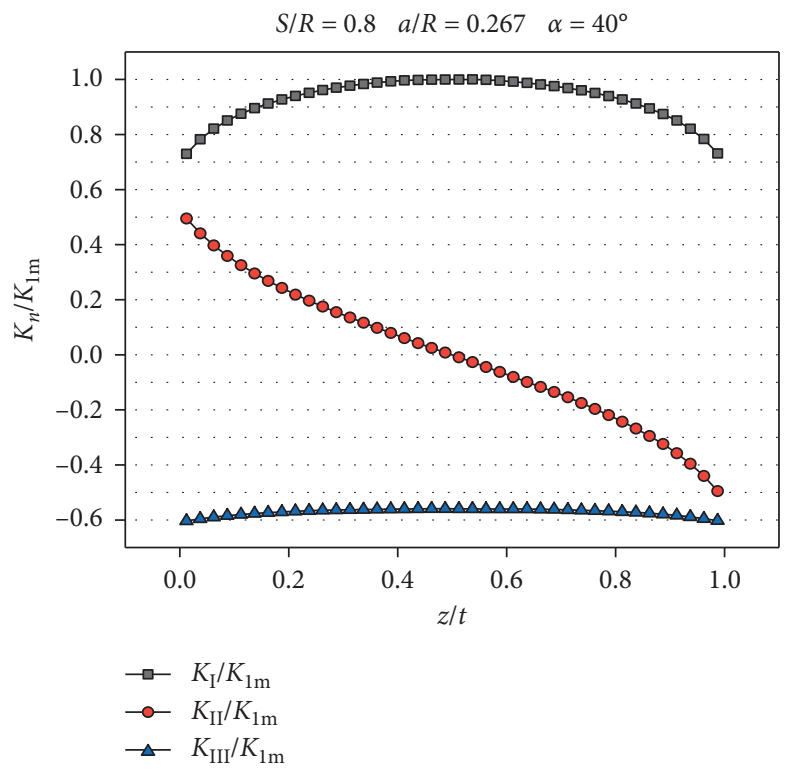

(c)

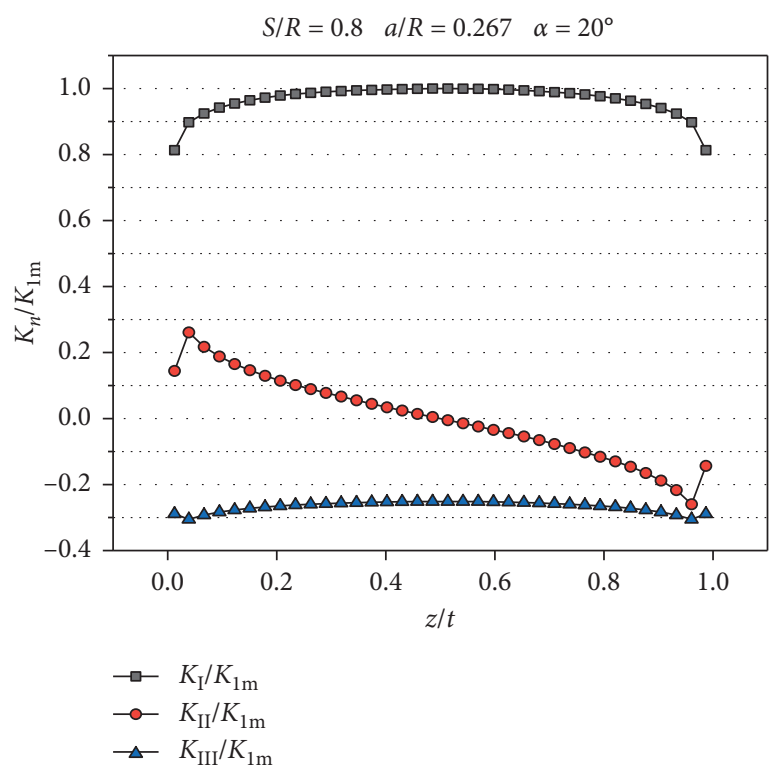

(b)

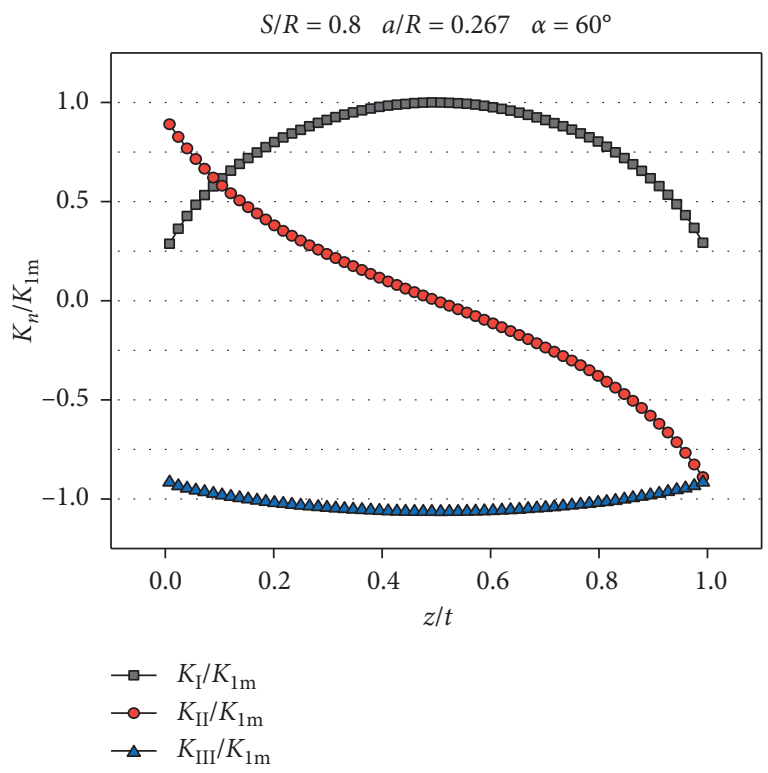

(d)

FIgURE 4: Variations of $K_{n} / K_{\operatorname{Im}}$ through crack front of the SCB specimen.

The mixity parameter $M^{e}$ can be used to describe the relative contributions of mode I and mode III, as expressed by equation (15). Under the condition of pure mode I, the value of $M^{e}$ is equal to one, and decreases as the contribution of mode III increases:

$$
M^{e}=\frac{2}{\pi} \tan ^{-1}\left(\frac{Y_{\mathrm{I}}}{Y_{\mathrm{III}}}\right) .
$$

To quantify the role of mode I and mode III in the numerical simulation, we propose to substitute equation (16) for equation (15), and the parameter $\left|M^{e}\right|$ can vary from 0 to 1 , corresponding to the pure mode III and mode I loading conditions, respectively:

$$
\left|M^{e}\right|=\frac{2}{\pi}\left|\tan ^{-1}\left(\frac{Y_{\mathrm{I}}}{Y_{\mathrm{III}}}\right)\right| .
$$

\section{Results and Discussion}

3.1. Numerical Calculation Results and Analysis. The crack length ratio $(a / R)$ remained unchanged at 0.267 and $a=20 \mathrm{~mm}$. The influences of the crack angle $(\alpha)$, half of the loading point span ratio $(S / R)$, and Poisson's ratio $(v)$ for $Y_{\mathrm{I}}$, $Y_{\mathrm{III}}$, and $\left|M^{e}\right|$ were investigated. Figures 5 and 6 show the variations of $Y_{\mathrm{I}}, Y_{\mathrm{III}}$, and $\left|M^{e}\right|$, with a crack inclination angle $(\alpha)$ for different values of $S / R$ and $v$ in the SCB specimen. 


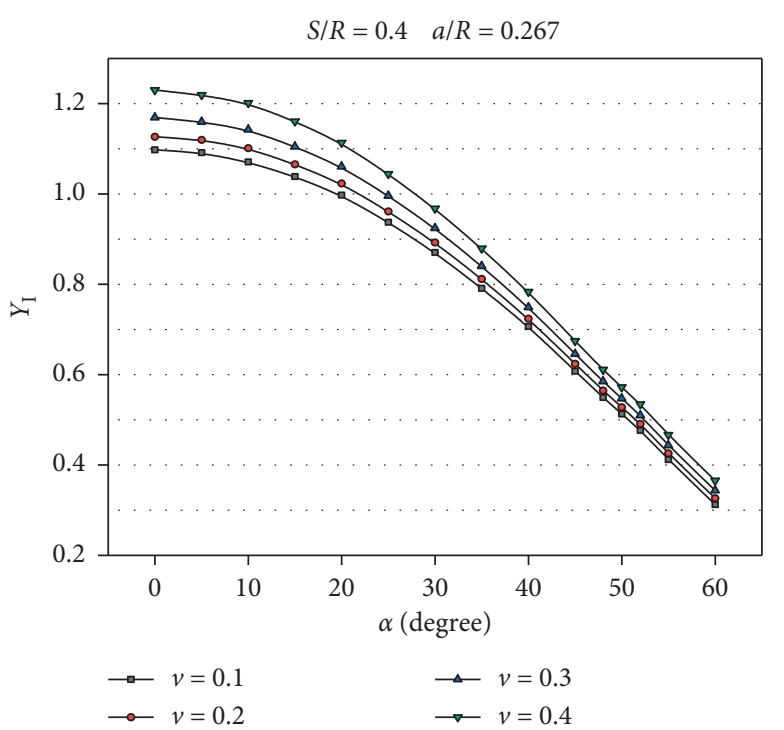

(a)

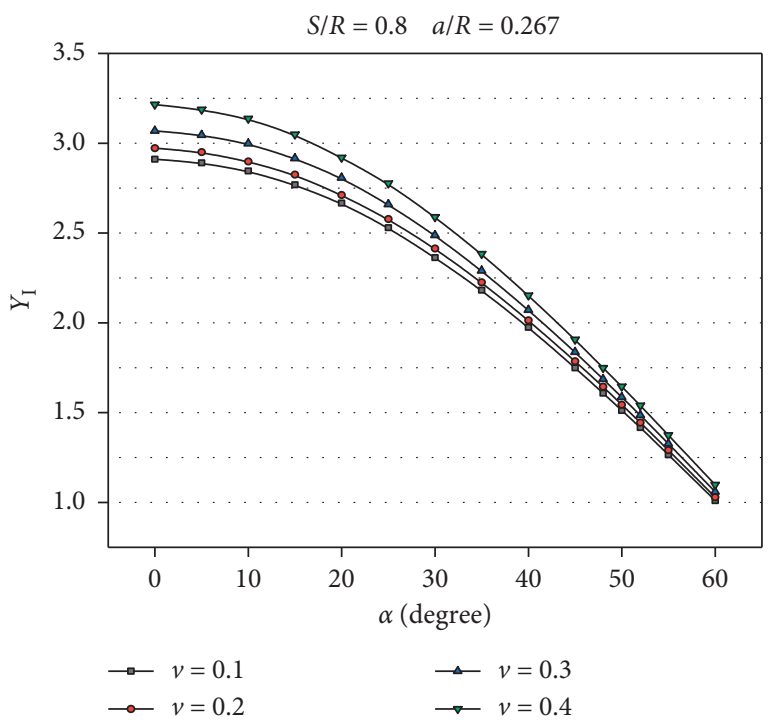

(c)

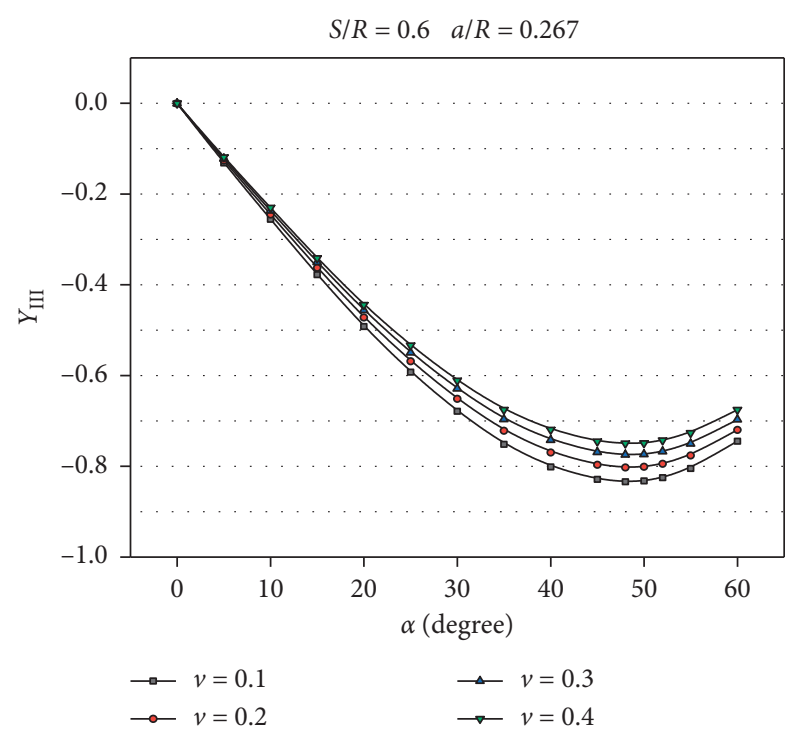

(e)

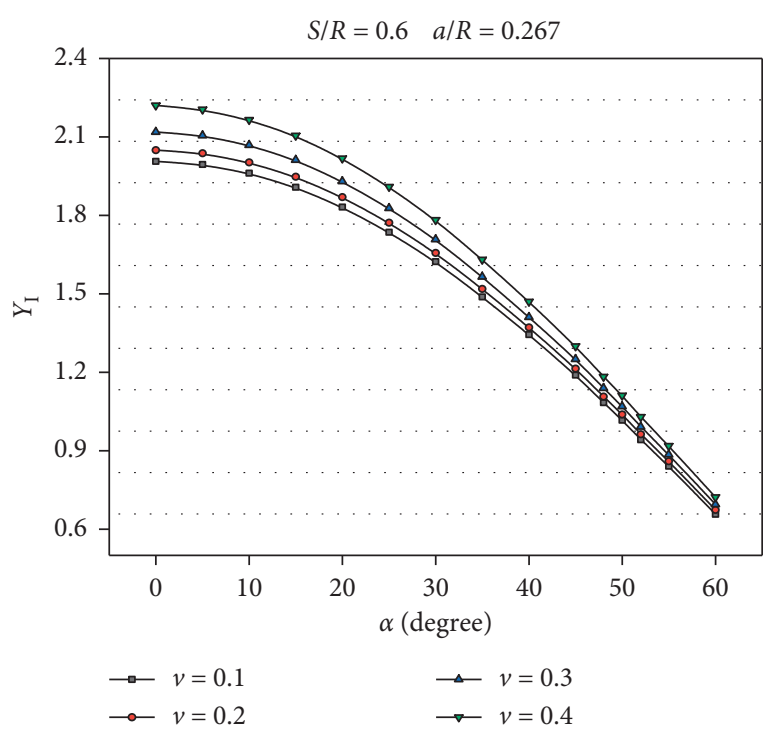

(b)

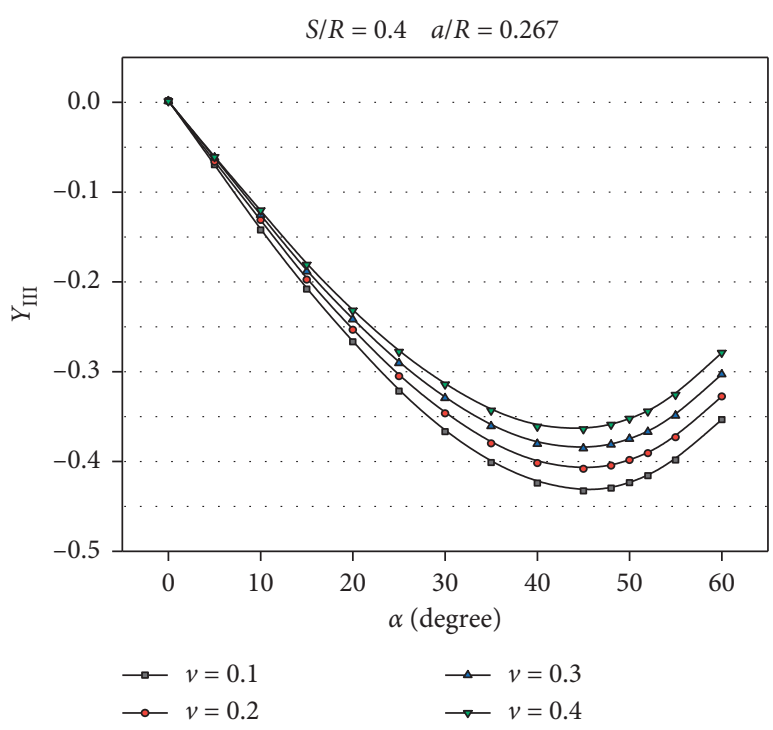

(d)

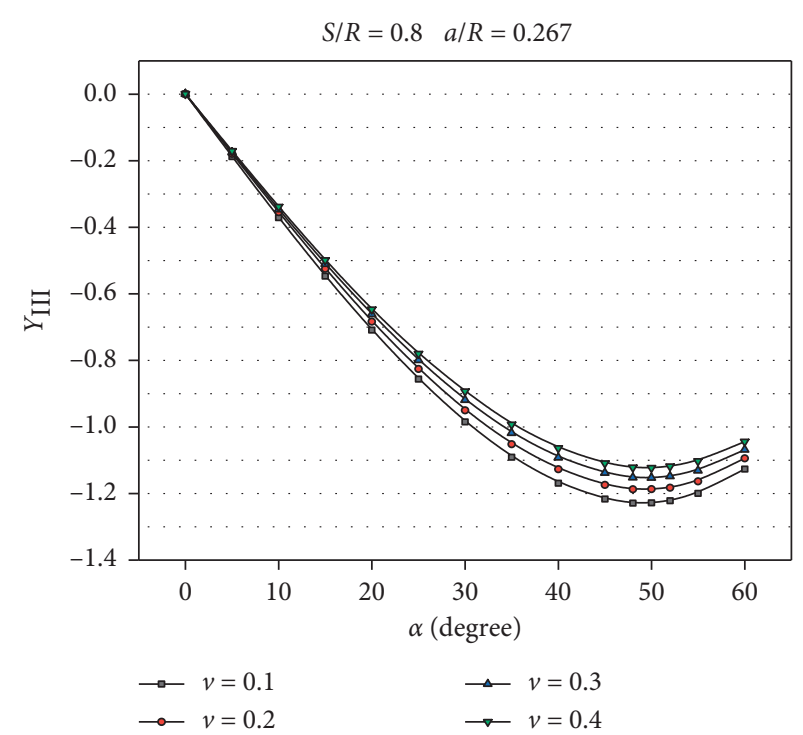

(f)

FIgURE 5: Variations of $Y_{\mathrm{I}}$ and $Y_{\mathrm{III}}$ with $\alpha$ for different $S / R$ and $v$ values in the SCB specimen. 


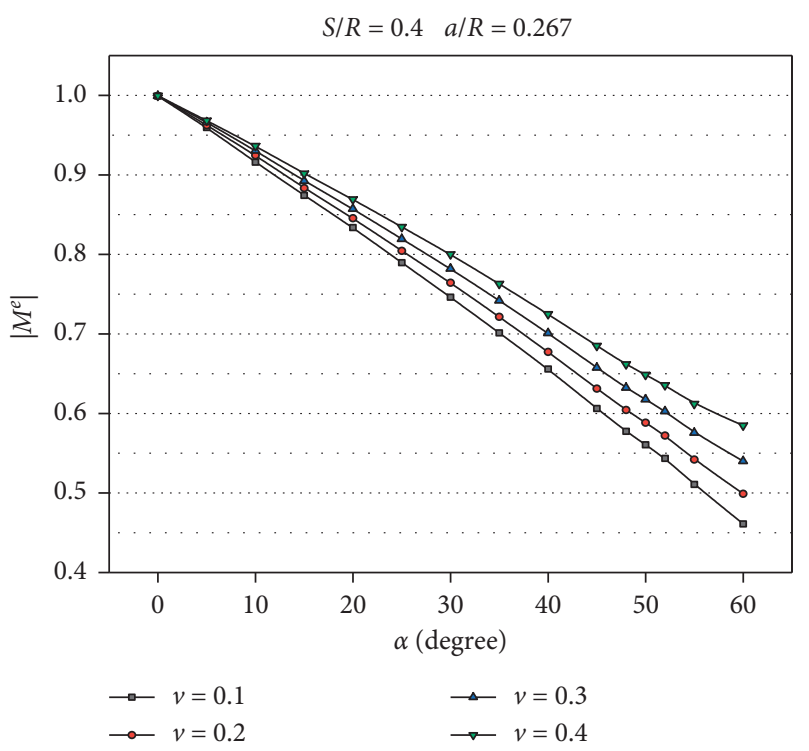

(a)

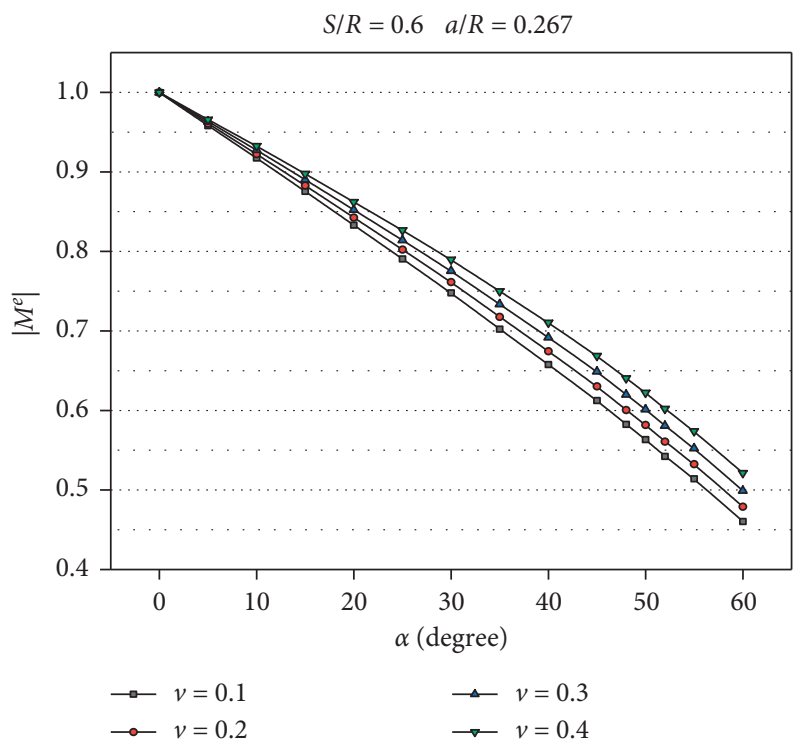

(b)

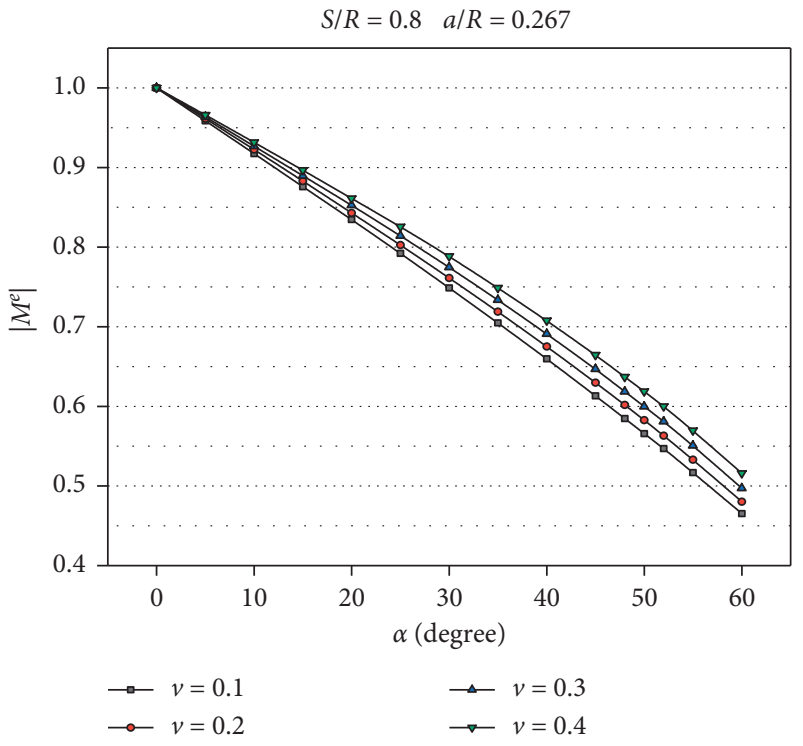

(c)

Figure 6: Variations of $\left|M^{e}\right|$ with $\alpha$ for different $S / R$ and $v$ values in the SCB specimen.

The following conclusions were drawn from image analysis:

(a) $Y_{\text {III }}$ remained at zero, only when $\alpha$ was $0^{\circ}$. For the same $\alpha$, the increase of $S / R$ and $v$ promoted the $Y_{\mathrm{I}}$. But for the $Y_{\mathrm{III}}$, the increase of $S / R$ and $v$ led to its decrease and increase, respectively.

(b) For the pure mode I $\left(\alpha=0^{\circ}\right)$, the increase of $v$ promoted the contribution of mode I, and the growth rate tended to increase.

(c) With the increase of $\alpha$, after entering the mixed mode I/III loading, the values of $Y_{\text {I }}$ gradually decreased, and $\left|Y_{\text {IIII }}\right|$ first increased and then decreased. Additionally, $\alpha$ corresponding to $\left|Y_{\mathrm{III}}\right|_{\max }$ slowly increased with the increase of $S / R$. The sensitivity of $Y_{\mathrm{I}}$ to the changes of $v$ decreased as $\alpha$ increased, and the sensitivity of $Y_{\text {III }}$ was maximum at $\left|Y_{I I I}\right|_{\max }$.

(d) The increase of $S / R$ only had a minor effect on the $M^{e} \mid$ values when $v$ was 0.1 of the SCB specimens. When the range of $v$ varied from 0.2 to 0.4 , the increase of $S / R$ obviously led to the decrease of $\left|M^{e}\right|$. Additionally, as $\alpha$ increased, the downtrend became more obvious.

Half of the loading point span ratio $(S / R)$ remained unchanged at $0.8, S=60 \mathrm{~mm}$, and the influences of the crack angle $(\alpha)$, crack length ratio $(a / R)$, and Poisson's ratio $(v)$ on $Y_{\mathrm{I}}, Y_{\mathrm{III}}$, and $\left|M^{e}\right|$ were investigated. Figures 7 and 8 show the variation of $Y_{\mathrm{I}}, Y_{\mathrm{III}}$, and $\left|M^{e}\right|$ with the crack inclination angle 


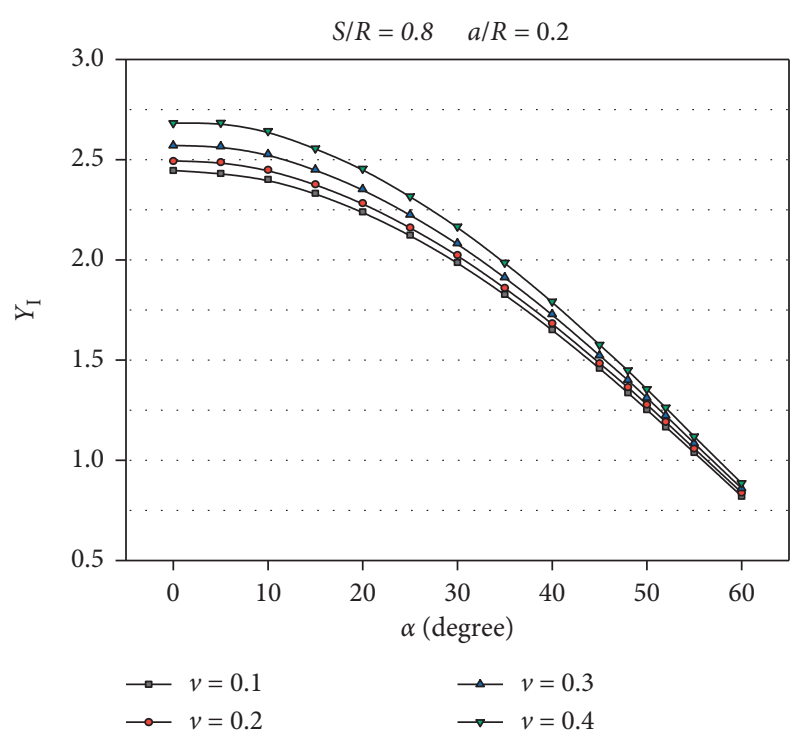

(a)

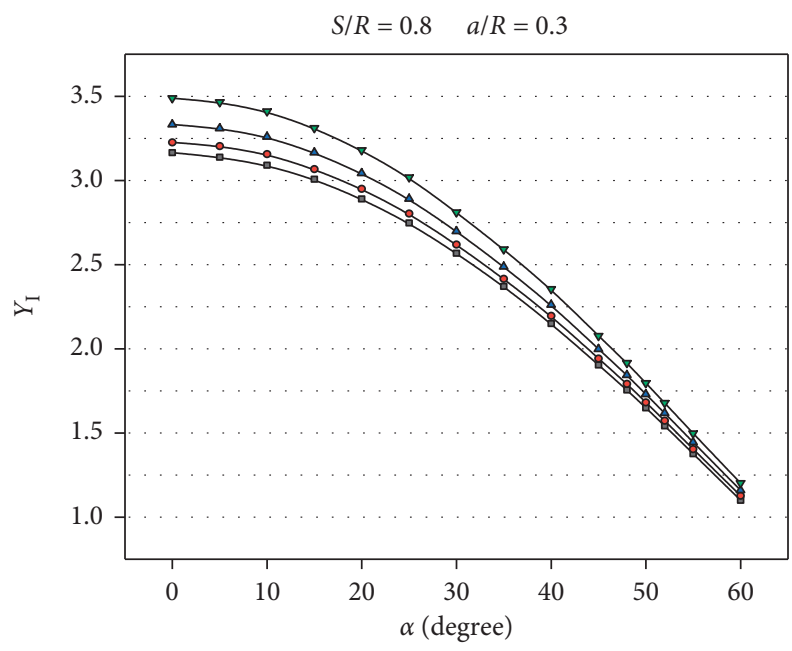

$\begin{aligned} \rightarrow & =0.1 \\ \rightarrow & v=0.2\end{aligned}$

$\rightarrow v=0.3$

(c)

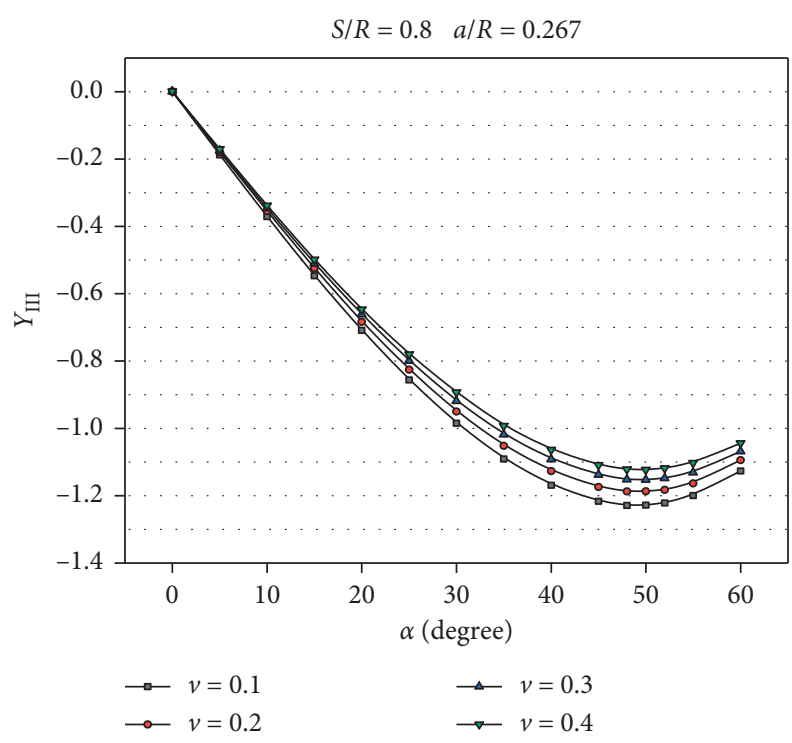

(e)

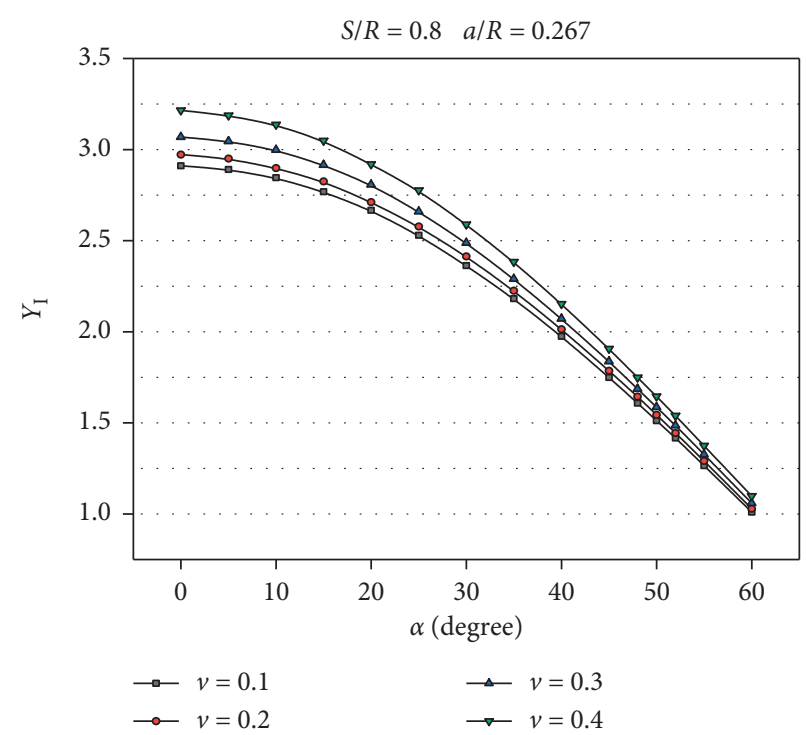

(b)

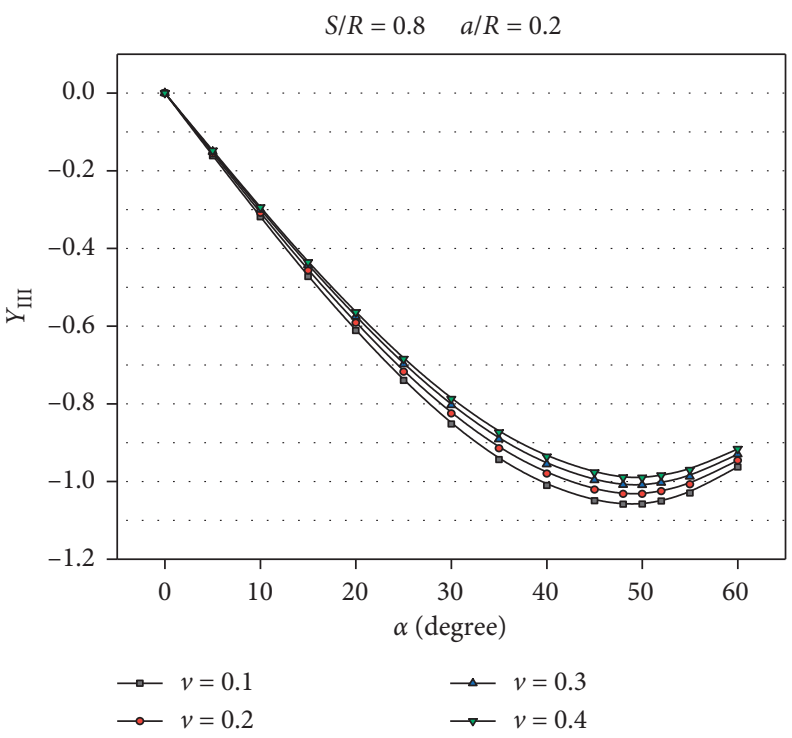

(d)

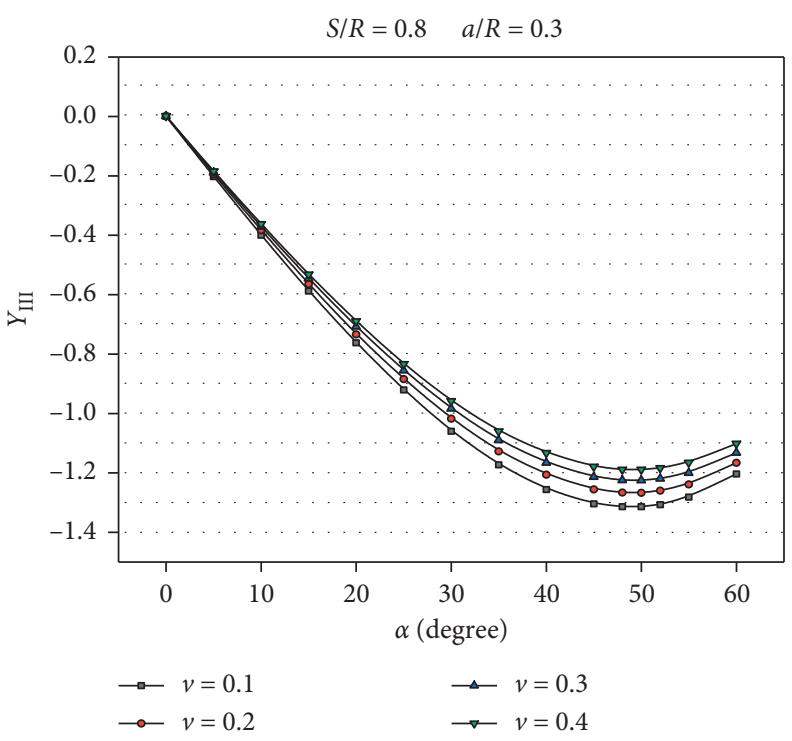

(f)

FIgURe 7: Variations of $Y_{\mathrm{I}}$ and $Y_{\text {III }}$ with $\alpha$ for different values of $a / R$ and $v$ in the SCB specimen. 


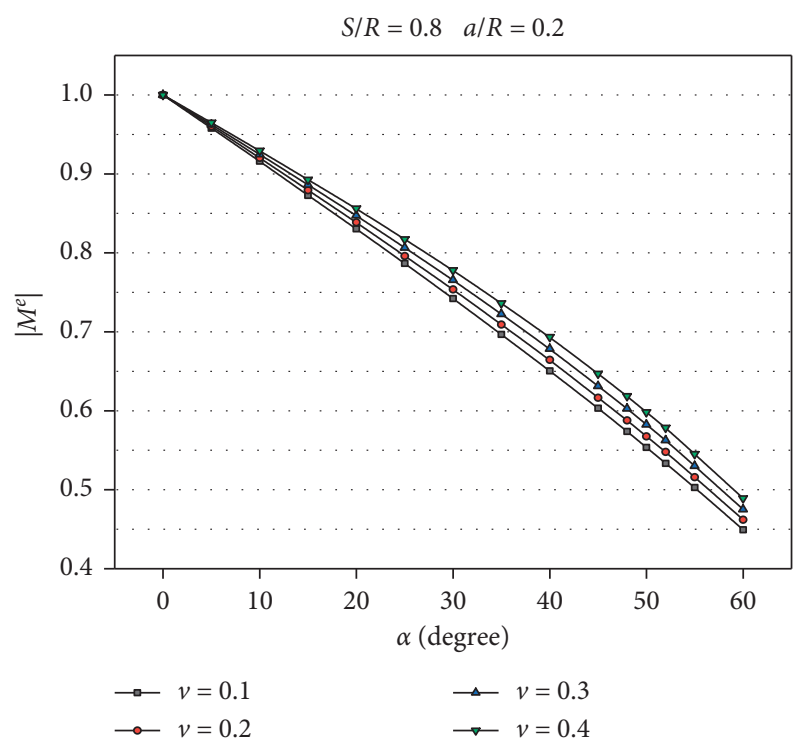

(a)

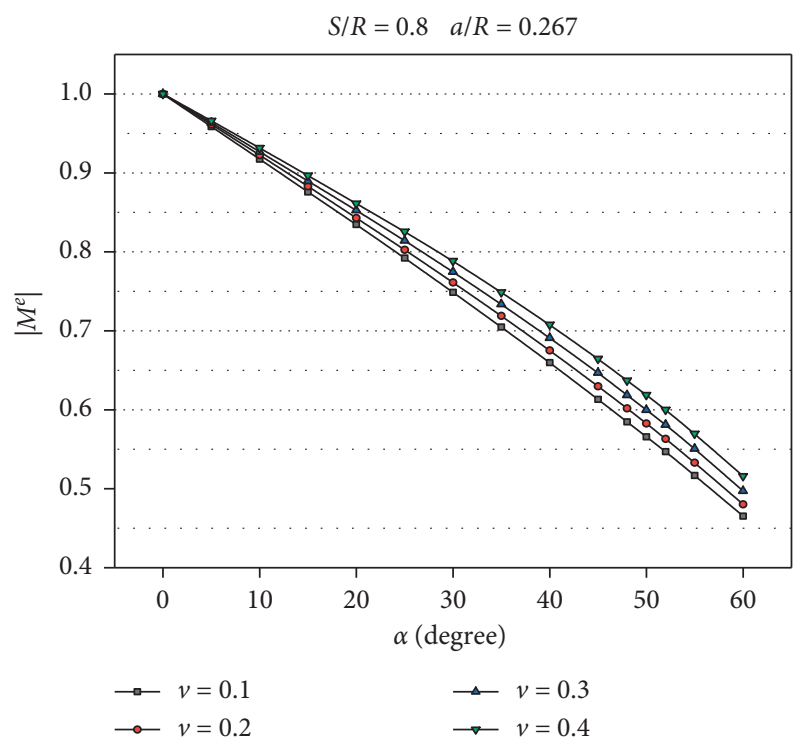

(b)

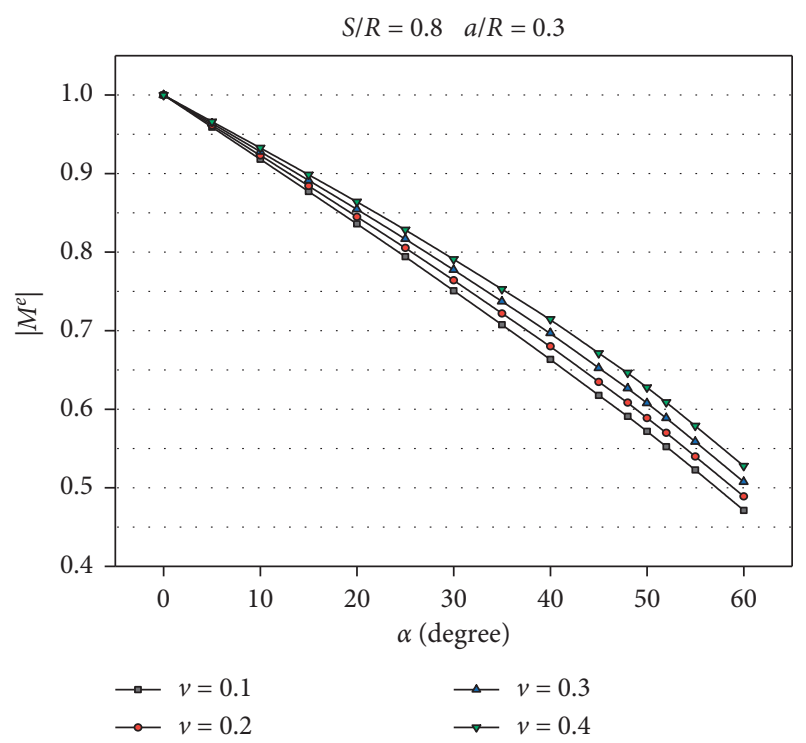

(c)

Figure 8: Variations of $\left|M^{e}\right|$ with $\alpha$ for different values of $a / R$ and $v$ in the SCB specimen.

$(\alpha)$ for different values of $a / R$ and $v$ in the SCB specimen. Figure 9 shows the $\left|M^{e}\right|_{\min }$ obtained with the change of $a / R$ and $v$.

The following conclusions were drawn from image analysis:

(a) For the same $\alpha$, the increase of $a / R$ and $v$ promoted the $Y_{\mathrm{I}}$ values. But for the $Y_{\mathrm{III}}$, the increase of $a / R$ and $v$ led to its decrease and increase, respectively.

(b) The value of $\alpha$ corresponding to $\left|Y_{\text {IIII }}\right|_{\max }$ stabilized at approximately $49^{\circ}$.

(c) For the values of $\left|M^{e}\right|$, the increase of $a / R$ led to the promotion of $M^{e}$; when the value of $a / R$ was relatively small, the influence of $v$ on $M^{e}$ was smaller under the same $\alpha$.

(d) The value of $\alpha$ was $60^{\circ}$, corresponding to the $\left|M^{e}\right|_{\text {min }}$ of all SCB specimens. As $v$ and $a / R$ became smaller, a smaller $\left|M^{e}\right|_{\min }$ value was obtained and the minimum value was 0.39 . In this case, the contribution of model III was obviously higher compared with that of model I. Additionally, for smaller $a / R, v$ only had a minor influence on $\left|M^{e}\right|_{\text {min }}$; however, when $a / R$ was larger, $\left|M^{e}\right|_{\min }$ was more sensitive to the variations of $v$.

Notably, the rule discussed in the previous section is not described. 


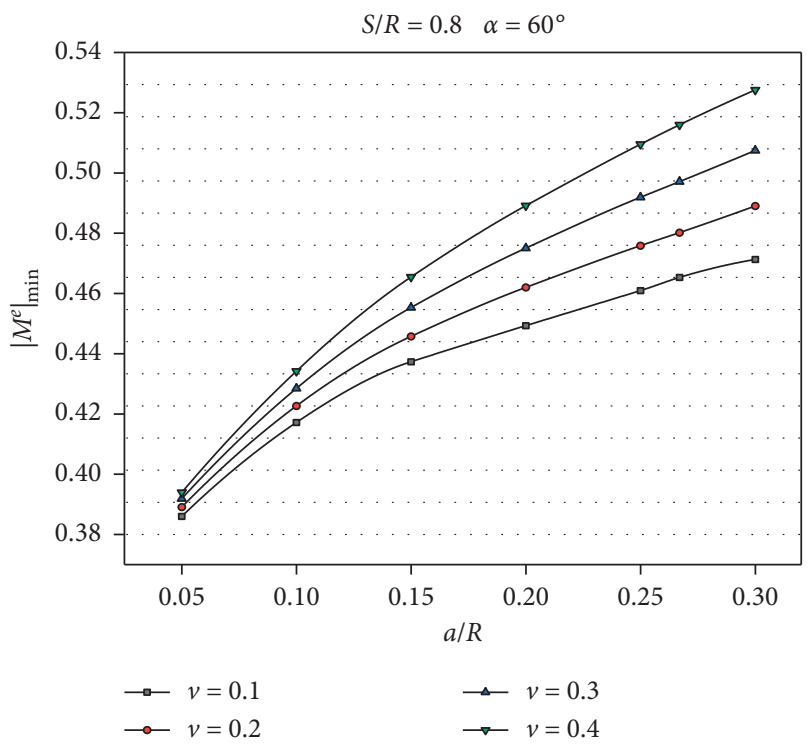

FIgURE 9: Variations of $\left|M^{e}\right|_{\min }$ for different values of $a / R$ and $v$ in the SCB specimen.
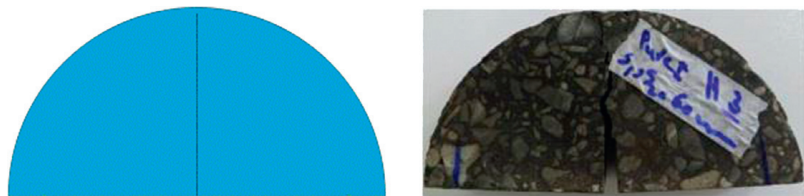

(a)
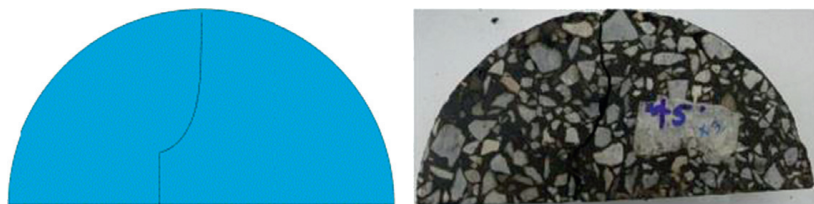

(c)
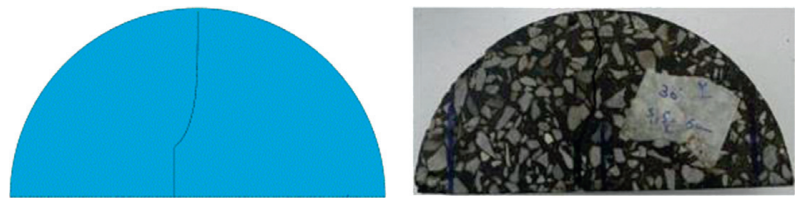

(b)
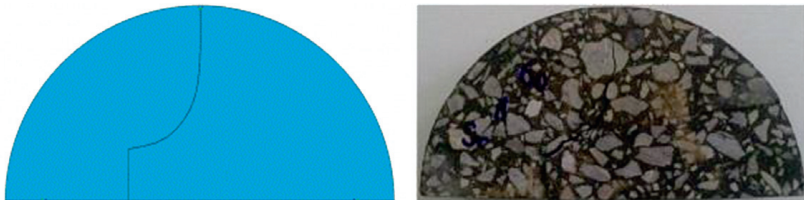

(d)

Figure 10: A comparison diagram between the paper [43] and numerical simulation of fracture path. (a) Pure mode I with $\alpha=0^{\circ}$; mixed mode I/III with (b) $\alpha=30^{\circ}$, (c) $\alpha=45^{\circ}$, (d) and $\alpha=60^{\circ}$.

3.2. Fracture Path Simulation. Using the $K_{\mathrm{I}}, K_{\mathrm{II}}$, and $K_{\mathrm{III}}$ values of the crack tip and the maximum tensile stress criterion (MTS), three model groups $(S / R=0.8 ; a / R=0.267$; $\alpha=0^{\circ}, 30^{\circ}, 45^{\circ}$, and $60^{\circ}$ ) were obtained for the crack failure and growth path, as shown in Figures 10 and 11. To facilitate the comparison, the failure mode after the image was flipped horizontally is in good agreement with the previous results [53].

Under mixed mode I/III loading conditions, the crack surface growth morphology was different from the inplane fracture. Figure 12(a) shows that, when an in-plane fracture (mode I, mode II, and mixed mode I/II) occurred, the crack surface remained in the same plane despite a certain deflection. However, Figure 12(b) shows that, when the mixed mode I/III fracture occurred, the crack surface was twisted and deviated from the direction of the crack surface by forming an angle called the kink angle.
Considering the direction of the crack kink angle $(\phi)$, the normal stress and shear stress components on the new plane can be obtained by carrying out coordinate transformation as follows:

$$
\begin{aligned}
\left\{\sigma_{y_{1} y_{1}}\right. & =\sigma_{\phi \phi}^{\mathrm{I}}=\left[\frac{K_{\mathrm{I}}}{(2 \pi r)^{1 / 2}}\right] g_{\phi \phi}^{\mathrm{I}}=\frac{K_{I}^{\prime}(\phi)}{(2 \pi r)^{1 / 2}}, \sigma_{x_{1} y_{I}}=\sigma_{x^{\prime} \phi}^{\mathrm{I}} \\
& =0=\frac{K_{\mathrm{II}}^{\prime}(\phi)}{(2 \pi r)^{1 / 2}}, \quad \sigma_{x_{\prime} z_{l}}=\sigma_{z^{\prime} \phi}^{I}=\left[\frac{K_{\mathrm{I}}}{(2 \pi r)^{1 / 2}}\right] g_{z^{\prime} \phi}^{\mathrm{I}} \\
& =\frac{K_{\mathrm{III}}^{\prime}(\phi)}{(2 \pi r)^{1 / 2}},
\end{aligned}
$$

where $x, y$, and $z$ are the original axes and $x^{\prime}, y^{\prime}$, and $z^{\prime}$ are the axes of the crack plane after deflection. The transformed stress intensity factor can be expressed as follows: 

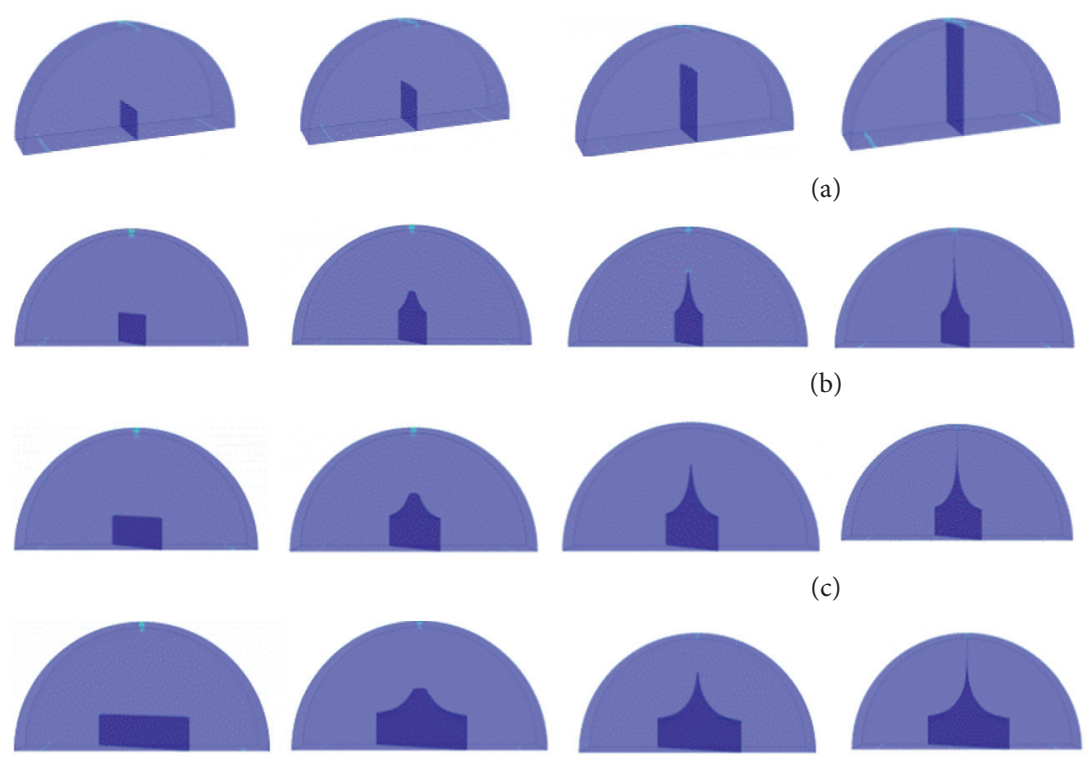

(d)

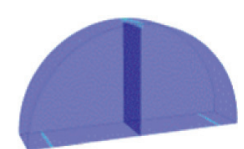

(a)
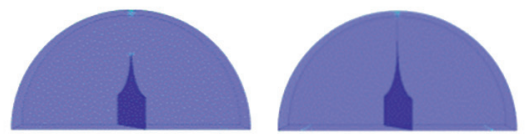

(b)
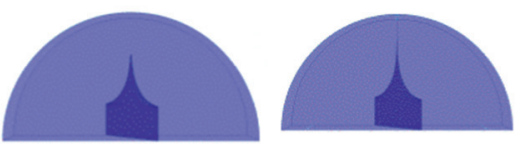

(c)
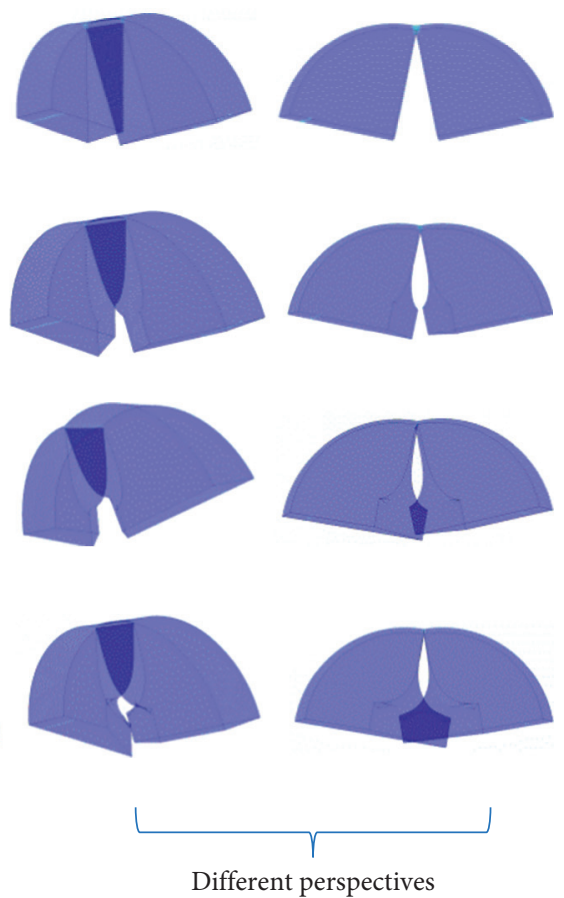

Crack propagation process

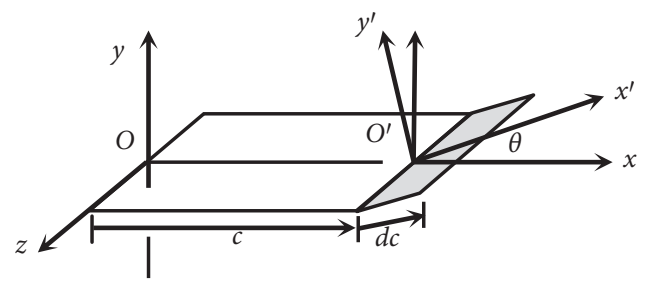

(a)

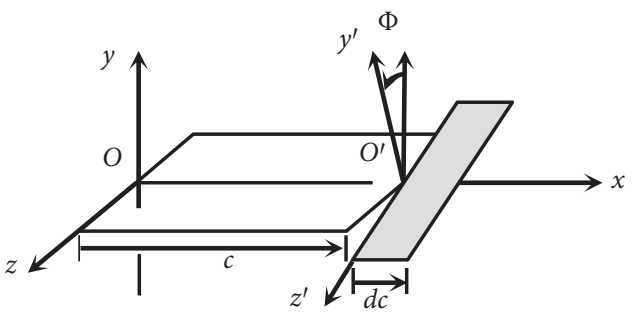

(b)

FIGURE 12: Nonplanar propagation mode of crack. (a) Crack surface deflection; (b) crack surface torsion.

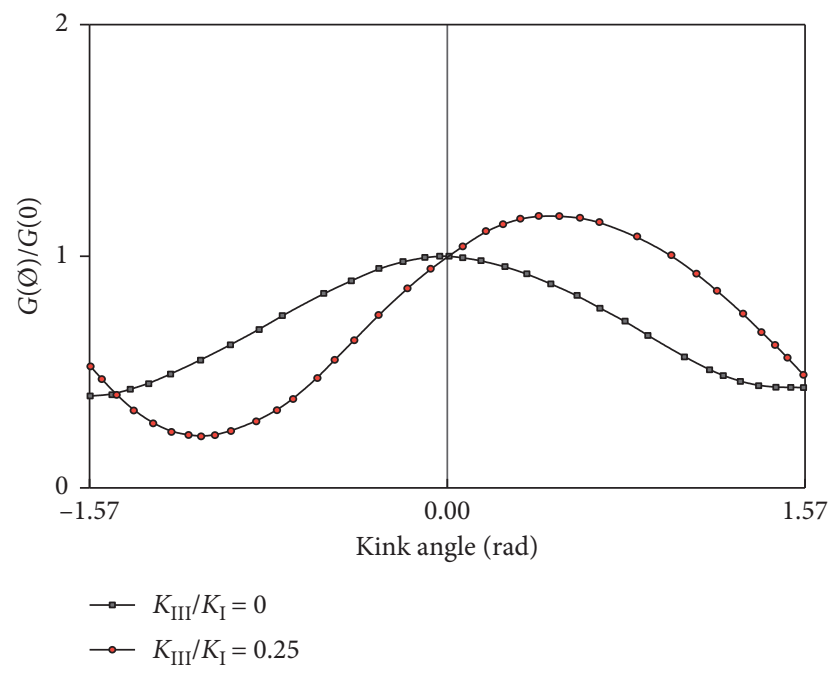

FIgURE 13: $G(\phi) / G(0)$ along with the change of kink angle $\phi$. 
TABLe 2: Variations of kink angle with $\alpha$ between 0.2 and 0.8 at the crack front.

\begin{tabular}{|c|c|c|c|c|c|c|c|}
\hline \multirow{2}{*}{$\alpha\left({ }^{\circ}\right)$} & \multicolumn{7}{|c|}{$z(\mathrm{t})$} \\
\hline & 0.2 & 0.3 & 0.4 & 0.5 & 0.6 & 0.7 & 0.8 \\
\hline 0 & 0.055 & 0.003 & 0.083 & 0.129 & 0.094 & -0.007 & 0.027 \\
\hline 10 & -5.691 & -3.742 & -2.034 & -0.008 & 2.198 & 4.115 & 6.070 \\
\hline 20 & -12.993 & -8.229 & -3.891 & 0.0435 & 3.933 & 8.833 & 13.207 \\
\hline 30 & -20.466 & -13.083 & -6.010 & 0.071 & 6.762 & 13.082 & 20.372 \\
\hline 40 & -25.093 & -16.241 & -7.939 & 0.055 & 8.163 & 16.276 & 25.144 \\
\hline 50 & -30.394 & -19.982 & -9.789 & -0.169 & 10.919 & 21.063 & 31.432 \\
\hline 60 & -39.125 & -24.966 & -12.113 & -0.025 & 13.049 & 26.081 & 40.163 \\
\hline
\end{tabular}

$$
\left\{K_{\mathrm{I}}^{\prime}(\phi)=K_{\mathrm{I}} g_{\phi \phi}^{\mathrm{I}}, K_{\mathrm{II}}^{\prime}(\phi)=0, K_{\mathrm{III}}^{\prime}(\phi)=K_{\mathrm{I}} g_{z^{\prime} \phi}^{\mathrm{I}}\right.
$$

The relationship between the release rate of the mechanical energy and the angle is expressed as follows:

$$
G(\phi)=\frac{K_{\mathrm{I}}^{\prime 2}(\phi)\left(1-v^{2}\right)}{E}+\frac{K_{\mathrm{III}}^{\prime 2}(\phi)(1+v)}{E} .
$$

By superposing the contributions of mode III, the corresponding transformed stress intensity factor can be expressed as follows.

By substituting equation (18) into equation (19), the expression of the release rate of the mechanical energy changing with the angle can be obtained for the mixed mode I/III. Figure 13 shows the normalization of the mechanical energy release rate along with the change of the crack kink angle $(\phi)$.

As can be seen in the graph, in the case of pure mode I fracturing $\left(K_{\mathrm{III}} / K_{\mathrm{I}}=0\right), G(\phi) / G(0)$ became maximum at the kink angle $(\phi)$ of $0^{\circ}$. Therefore, the pure mode I fracture extended in the direction of the original when the kink angle was $0^{\circ}$. When the superposition of the mode III contribution was added $\left(K_{\mathrm{III}} / K_{\mathrm{I}}=0.25\right)$, as shown in Figure 13 , the crack kink angle deviated from the original crack plane by an angle that can be considered as a correction by the contribution of mode III. Finally, the crack moved up in the direction perpendicular to the maximum principal tension and changed from mixed mode I/III to pure mode I. The numerical simulation results presented in Figure 10 reveal that the extension surface gradually returned to a plane from a curved surface close to the loading point and finally fractured close to the loading point. This phenomenon is consistent with the fact that the fracture surface is divided into three regions [53]. Table 2 presents the kink angle between 0.2 and 0.8 at the crack front with different $\alpha$, as extracted from Franc3D. The SCB specimen parameters were $S / R=0.8, a / R=0.267$, and $v=0.2$. Additionally, it was observed that the kink angle of the crack is related to $\alpha$, and a larger $\alpha$ resulted in a greater kink angle.

\section{Conclusions}

The following conclusions were drawn from this study:

(a) Numerical modeling combined with Abaqus and Franc3D analysis was used to investigate the influence of half of the loading point span ratio $(S / R)$, crack length ratio $(a / R)$, crack angle $(\alpha)$, and
Poisson's ratio $(v)$ on the behavior of mixed mode I/ III loading.

(b) The increase of $S / R, a / R$, and $v$ promoted the dimensionless parameters $Y_{\mathrm{I}}$. But for the $Y_{\mathrm{III}}$, only the increase of $a / R$ and $S / R$ led to its decrease. As $\alpha$ increased, the sensitivity of $Y_{I}$ decreased with the changes of $v$, while the sensitivity of $Y_{\text {III }}$ became maximum at $\left|Y_{\mathrm{III}}\right|_{\max }$.

(c) The obvious approach toward reducing the mixity parameter $\left|M^{e}\right|$ is to decrease $\alpha$. Additionally, it is possible to reduce $\left|M^{e}\right|$ by changing $S / R$ or $a / R$. Moreover, the SCB specimen materials with small $v$ exhibited the best reduction effect.

(d) The $\left|M^{e}\right|_{\text {min }}$ values of the SCB specimens were obtained under different $a / R$ and $v$, which can be useful as a references for SCB specimens of different materials subjected to mixed mode I/III loading tests.

(e) The numerical parameters obtained by the $M$-integral were used to simulate the crack growth and failure path, which are in good agreement with previous experimental results. The relationship between $\alpha$ and the kink angle $(\phi)$ was quantitatively analyzed, and their positive correlation was confirmed. The proposed method can be used to simulate the fracture path under mixed mode I/III loading.

\section{Data Availability}

All data used to support the findings of this study are included within the article.

\section{Conflicts of Interest}

There is no conflicts of interest regarding the publication of this paper.

\section{Acknowledgments}

The authors gratefully acknowledge Senior Engineer Haijun Wang and Dr. Shuyang Yu for their supports in this research program, and they also extend their thanks to the National Key R\&D Program of China (2017YFC0404902), the National Natural Science Foundation of China (51739008), the Natural Science Foundation of Jiangsu Province of China (BK20171130), and the basic scientific research operating 
expenses of the Public Welfare Scientific Research Institutes at the Central Level of China (Y419005).

\section{References}

[1] D. Mahinda and K. P. C. Kuruppu, "Fracture toughness testing of brittle materials using semi-circular bend (SCB) specimen," Engineering Fracture Mechanics, vol. 91, no. 1, pp. 133-150, 2012.

[2] K. P. Chong and M. D. Kuruppu, "New specimen for fracture toughness determination of rock and other materials," International Journal of Fracture, vol. 26, no. 2, pp. R59-R62, 1984.

[3] K. P. Chong, M. D. Kuruppu, and J. S. Kuszmaul, "Fracture toughness determination of layered materials," Engineering Fracture Mechanics, vol. 28, no. 1, pp. 43-54, 1987.

[4] K. P. Chong, K. D. Basham, and W. D. Qing, "Fracture parameters derived from tension-softening measurements using semi-circular specimens," International Journal of Rock Mechanics \& Mining Sciences \& Geomechanics Abstracts, vol. 28, no. 6, p. A398, 1991.

[5] K. P. Chong and M. D. Kuruppu, "Mixed mode fracture analysis using new semi-circular specimens," Computers \& Structures, vol. 30, no. 4, pp. 905-908, 1988.

[6] K. P. Chong and M. D. Kuruppu, "New specimens for mixed mode fracture investigations of geomaterials," Engineering Fracture Mechanics, vol. 30, no. 5, pp. 701-712, 1988.

[7] B. N. Whittaker, R. N. Singh, and Sun Gexin, "Rock fracture mechanics principles, design and applications," Rock Fracture Mechanics:principles, Design, and Applications, vol. 71, p. 275, 1992.

[8] I. L. Lim, I. W. Johnston, and S. K. Choi, "Assessment of mixed-mode fracture toughness testing methods for rock," International Journal of Rock Mechanics and Mining Sciences \& Geomechanics Abstracts, vol. 31, no. 3, pp. 265-272, 1994.

[9] I. L. Lim, I. W. Johnston, S. K. Choi, and J. N. Boland, "Fracture testing of a soft rock with semi-circular specimens under three-point bending. Part 1-mode I," International Journal of Rock Mechanics and Mining Sciences \& Geomechanics Abstracts, vol. 31, no. 3, pp. 185-197, 1994.

[10] I. L. Boland, I. W. Johnston, and S. K. Choi, "Stress intensity factors for semi-circular specimens under three-point bending," Engineering Fracture Mechanics, vol. 44, no. 3, pp. 363-382, 1993.

[11] M. R. Ayatollahi, M. R. M. Aliha, and M. M. Hassani, "Mixed mode brittle fracture in PMMA - an experimental study using SCB specimens," Materials Science \& Engineering A (Structural Materials:, Properties, Microstructure and Processing), vol. 417, no. 1-2, pp. 348-356, 2006.

[12] M. D. Kuruppu, Y. Obara, K. P. Chong, and T. Funatsu, "ISRM-suggested method for determining the mode I static fracture toughness using semi-circular bend specimen," Rock Mechanics and Rock Engineering, vol. 47, no. 1, pp. 267-274, 2014.

[13] M. R. M. Funatsu and M. R. Ayatollahi, "Mixed mode I/II brittle fracture evaluation of marble using SCB specimen," Procedia Engineering, vol. 10, no. 1, pp. 311-318, 2011.

[14] W. Wang, J. E. Olson, M. Prodanović, and R. A. Schultz, "Interaction between cemented natural fractures and hydraulic fractures assessed by experiments and numerical simulations," Journal of Petroleum Science and Engineering, vol. 167 , no. 3 , pp. 506-516, 2018.

[15] D. Singh, P. K. Ashish, and S. F. Chitragar, "Laboratory performance of recycled asphalt mixes containing wax and chemical based Warm mix additives using semi circular bending and tensile strength ratio tests," Construction and Building Materials, vol. 158, no. 10, pp. 1003-1014, 2018.

[16] J. Akbardoost, M. R. Ayatollahi, M. R. M. Aliha, M. J. Pavier, and D. J. Smith, "Size-dependent fracture behavior of guiting limestone under mixed mode loading," International Journal of Rock Mechanics \& Mining Sciences, vol. 71, pp. 369-380, 2018.

[17] M. R. M. Aliha, H. Behbahani, and M. H. Rezaifar, "Study of characteristic specification on mixed mode fracture toughness of asphalt mixtures," Construction and Building Materials, vol. 54, no. 12, pp. 623-635, 2014.

[18] B. Huang, G. X. Shu, and G. Zuo, "Using notched semi circular bending fatigue test to characterize fracture resistance of asphalt mixtures," Engineering Fracture Mechanics, vol. 109, no. 12, pp. 78-88, 2013.

[19] C. Jiang, G.-F. Zhao, J. Zhu, Y.-X. Zhao, and L. Shen, "Investigation of dynamic crack coalescence using a gypsum-like 3D printing material," Rock Mechanics and Rock Engineering, vol. 49, no. 10, pp. 3983-3998, 2016.

[20] B. Birgisson, A. Montepara, E. Romeo et al., "Determination and prediction of crack patterns in hot mix asphalt (HMA) mixtures," Engineering Fracture Mechanics, vol. 75, no. 3-4, pp. 664-673, 2008.

[21] G. Feng, Y. Kang, T. Meng, Y.-Q. Hu, and X.-H. Li, “The influence of temperature on mode I fracture toughness and fracture characteristics of sandstone," Rock Mechanics and Rock Engineering, vol. 50, no. 8, pp. 2007-2019, 2017.

[22] M. Ameri, M. S. Nowbakht, and M. R. M. Aliha, "Investigation of fatigue and fracture properties of asphalt mixtures modified with carbon nanotubes," Fatigue \& Fracture of Engineering Materials \& Structures, vol. 39, no. 7, pp. 896906, 2016.

[23] M. R. M. Aliha, A. Bahmani, and S. Akhondi, "Mixed mode fracture toughness testing of PMMA with different threepoint bend type specimens," European Journal of Mechanics-A/Solids, vol. 58, no. 1, pp. 148-162, 2016.

[24] M. R. M. Aliha, M. R. Ayatollahi, and J. Akbardoost, "Typical upper bound-lower bound mixed mode fracture resistance envelopes for rock material," Rock Mechanics and Rock Engineering, vol. 45, no. 1, pp. 65-74, 2012.

[25] H. Saghafi, M. R. Ayatollahi, and M. Sistaninia, "A modified MTS criterion (MMTS) for mixed-mode fracture toughness assessment of brittle materials," Materials Science \& Engineering: A (Structural Materials: Properties, Microstructure and Processing), vol. 527, no. 21-22, pp. 5624-5630, 2010.

[26] X.-J. Li and M. O. Marasteanu, "Using semi circular bending test to evaluate low temperature fracture resistance for asphalt concrete," Experimental Mechanics, vol. 50, no. 7, pp. 867876, 2010.

[27] M. R. M. Aliha, M. R. Ayatollahi, D. J. Smith, and M. J. Pavier, "Geometry and size effects on fracture trajectory in a limestone rock under mixed mode loading," Engineering Fracture Mechanics, vol. 77, no. 11, pp. 2200-2212, 2010.

[28] I. Pavier and H. A. Khalid, "A comparison between beam and semi-circular bending fracture tests for asphalt," Road Materials and Pavement Design, vol. 7, no. 1, pp. 163-180, 2006.

[29] M. R. Ayatollahi and M. R. M. Aliha, "On determination of mode II fracture toughness using semi-circular bend specimen," International Journal of Solids and Structures, vol. 43, no. 17, pp. 5217-5227, 2006.

[30] C. Li, L. Xie, J. Li Ren et al., "Evaluating the applicability of fracture criteria to predict the crack evolution path of 
dolomite based on SCB experiments and FEM," Advances in Civil Engineering, vol. 2013, Article ID 959806, 13 pages, 2013.

[31] M. Eftekhari, H. A. Baghbanan, and H. Hashemolhosseini, "Fracture propagation in a cracked semicircular bend specimen under mixed mode loading using extended finite element method," Arabian Journal of Geosciences, vol. 8, no. 11, pp. 9635-9646, 2015.

[32] A. S. Fayed, "Numerical evaluation of mode I/II SIF of quasibrittle materials using cracked semi-circular bend specimen," Engineering Solid Mechanics, vol. 6, no. 2, pp. 175-186, 2018.

[33] T. Xiaoge, R. Zhang, Z. Yang, Y. Chu, S. Zhen, and Y. Xv, "Simulation of bending fracture process of asphalt mixture semicircular specimen with extended finite element method," Advances in Civil Engineering, vol. 2018, Article ID 4081264, 8 pages, 2018.

[34] W. S. Johnson, J. E. Masters, T. K. O’brien, and S. K. Lee, “An edge crack torsion method for mode III delamination fracture testing," Journal of Composites Technology and Research, vol. 15, no. 3, pp. 193-201, 1993.

[35] J. G. Lee, "Characterization of the edge crack torsion (ECT) test for mode III fracture toughness measurement of laminated composites," Journal of Endocrinology, vol. 82, no. 3, pp. 403-408, 2004.

[36] D. Pennas, W. J. Cantwell, and P. Compston, "The influence of strain rate on the mode III interlaminar fracture of composite materials," Journal of Composite Materials, vol. 41, no. 21, pp. 2595-2614, 2007.

[37] M. Farshad and P. Flueler, "Investigation of mode III fracture toughness using an anti-clastic plate bending- method," Engineering Fracture Mechanics, vol. 60, no. 5-6, pp. 597-603, 1998.

[38] M. F. S. F. de Moura, M. V. C. Fernande, A. B. Morais, and R. D. S. G. Campilho, "Numerical analysis of the edge crack torsion test for mode III interlaminar fracture of composite laminates," Engineering Fracture Mechanics, vol. 76, no. 4, pp. 469-478, 2009.

[39] X. Gao and C. Fong Shih, "A parametric study of mixed-mode I/III ductile fracture in tough materials under small scale yielding," Engineering Fracture Mechanics, vol. 60, no. 4, pp. 407-420, 1998.

[40] B. Lin, M. E. Mear, and K. Ravi-Chandar, "Criterion for initiation of cracks under mixed-mode I + III loading," International Journal of Fracture, vol. 165, no. 2, pp. 175-188, 2010.

[41] F. Berto and P. Lazzarin, "Recent developments in brittle and quasi-brittle failure assessment of engineer-ing materials by means of local approaches," Materials Science and Engineering: R: Reports, vol. 75, pp. 1-48, 2014.

[42] F. Ayatollahi, M. Elices, P. Lazzarin, and M. Zappalorto, "Fracture behaviour of notched round bars made of PMMA subjected to torsion at room temperature," Engineering Fracture Mechanics, vol. 90, no. 5, pp. 143-160, 2012.

[43] F. Zappalorto, P. Lazzarin, and M. R. Ayatollahi, "Brittle fracture of sharp and blunt V-notches in isostatic graphite under torsion loading," Carbon, vol. 50, no. 5, pp. 1942-1952, 2012.

[44] F. Berto, D. A. Cendon, P. Lazzarin, and M. Elices, "Fracture behaviour of notched round bars made of PMMA subjected to torsion at $-60^{\circ} \mathrm{C}$, "Engineering Fracture Mechanics, vol. 102, no. 2, pp. 271-287, 2013.

[45] F. Elices, M. Ayatollahi, and A. Campagnolo, "Fracture tests under mixed mode I + III loading: an assessment based on the local energy," International Journal of Damage Mechanics, vol. 26, no. 6, pp. 881-894, 2017.
[46] M. R. M. Aliha, A. Bahmani, and S. Akhondi, "Numerical analysis of a new mixed mode I/III fracture test specimen," Engineering Fracture Mechanics, vol. 134, no. 12, pp. 95-110, 2015.

[47] M. R. M. Aliha, A. Bahmani, and S. Akhondi, "Determination of mode III fracture toughness for different materials using a new designed test configuration," Materials \& Design, vol. 86, no. 8, pp. 863-871, 2015.

[48] M. R. M. Aliha, A. Bahmani, and S. Akhondi, "A novel test specimen for investigating the mixed mode I+ III fracture toughness of hot mix asphalt composites-experimental and theoretical study," International Journal of Solids and Structures, vol. 90, no. 3, pp. 167-177, 2016.

[49] M. R. M. Aliha and A. Bahmani, "Rock fracture toughness study under mixed mode I/III loading," Rock Mechanics and Rock Engineering, vol. 50, no. 7, pp. 1739-1751, 2017.

[50] E. Linul and L. Marsavina, "Experimental determination of mixed-mode fracture toughness for rigid polyurethane foams," Fracture at all Scales, Springer, Berlin, Germany, pp. 221-237, 2016.

[51] M. R. M. Aliha, E. Linul, A. Bahmani, and L. Marsavina, "Experimental and theoretical fracture toughness investigation of PUR foams under mixed mode I + III loading," Polymer Testing, vol. 67, no. 2, pp. 75-83, 2018.

[52] S. Marsavina and A. Kiani, "Study on fracture behavior of HMA mixtures under mixed mode I/III loading," Engineering Fracture Mechanics, vol. 153, no. 4, pp. 80-90, 2016.

[53] M. R. Ayatollahi and M. R. M. Aliha, "Wide range data for crack tip parameters in two disc-type specimens under mixed mode loading," Computational Materials Science, vol. 38, no. 4, pp. 660-670, 2007.

[54] M. R. M. Aliha and H. Saghafi, "The effects of thickness and poisson's ratio on 3D mixed-mode fracture," Engineering Fracture Mechanics, vol. 98, no. 1, pp. 15-28, 2013.

[55] F. Z. Li, C. F. Shih, and A. Needleman, "A comparison of methods for calculating energy release rates," Engineering Fracture Mechanics, vol. 21, no. 2, pp. 405-421, 1985.

[56] L. Banks-Sills, P. A. Wawrzynek, B. Carter, A. R. Ingraffea, and I. Hershkovitz, "Methods for calculating stress intensity factors in anisotropic materials: part II-arbitrary geometry," Engineering Fracture Mechanics, vol. 74, no. 8, pp. 1293-1307, 2007.

[57] J. H. Ingraffea and A. J. Chien, "Evaluation of M-integral for anisotropic elastic media with multiple defects," International Journal of Fracture, vol. 114, no. 3, pp. 267-289, 2002.

[58] Z. P. Bažant and L. F. Estenssoro, "Surface singularity and crack propagation," International Journal of Solids \& Structures, vol. 15, no. 5, pp. 405-426, 1979. 